\title{
Welfare States Matter for Democracy: Income-based Participatory Inequality in Post-WWII Western Democracies
}

\section{Constantin Manuel Bosancianu}

Research Fellow, Wissenschaftszentrum Berlin (WZB)

Institutions and Political Inequality research unit

Reichpietschufer 50, 10785 Berlin, Germany

manuel.bosancianu@wzb.eu

\section{Carsten Q. Schneider}

Professor, Department of Political Science

Central European University (CEU)

Quellenstraße 51, A-1100 Vienna, Austria

schneiderc@ceu.edu 


\begin{abstract}
Poorer citizens generally participate less in politics; at the same time, the income-based gap in participation is not the same across democracies. Whereas in Denmark in 1977 turnout among poorer citizens was 6 percentage points higher than among wealthier ones, in the United States in 1988 the gap is reversed: turnout among wealthier Americans is 31 percentage points higher than among their poorer peers. Existing attempts at understanding the sources of this variation point to macro-level factors, such as compulsory voting, ballot complexity, or income inequality (Gallego, 2015; Solt, 2008). Though important, we argue that existing accounts aren't successful in explaining temporal variation in this participation gap, over periods of time in which the institutional framework is stable. We propose instead a largely neglected, yet plausible, reason for why a differential effect of income on political participation exists: the characteristics of the welfare state. In addition to providing resources relevant to participation, welfare state arrangements also create political constituencies that can be mobilized around a shared goal by political entrepreneurs. Building on Schneider and Makszin's (2014) education-based analysis we inductively develop, with the use of Qualitative Comparative Analysis (QCA), various welfare regime types that condition patterns of income-based participatory inequality in democracies. These are produced based on an original data set of roughly 150 merged surveys from 19 OECD members, between 1960 and 2010. We label these types the supportive and mobilizing welfare regimes, along with their non-mobilizing and non-supportive counterparts.

These welfare state regimes correspond to different mechanisms through which welfare state characteristics shape participatory patterns: (1) resource endowments available to individuals for participation and (2) unions' and parties' ability to politically mobilize and inform their members. We complement our aggregate-level QCA analysis with individual-level tests of these hypothesized mechanisms. Relying on six cross-national survey programs, such as the European Social Survey or the Comparative Study of Electoral Systems, we find consistent support for the mobilization-based mechanisms, while revealing mixed evidence that they also spill over into attitudinal factors which underpin participation. Only weaker evidence is found for our resource-based mechanisms. Overall, our results indicate the effect of welfare state characteristics on political participation gaps in advanced industrial democracies. Welfare state reforms, and in particular retrenchment, are likely to have (damaging) consequences for democracy.
\end{abstract}

Acknowledgements: Past versions of this paper have been presented at the IPSA World Congress of Political Science (July 2016), as well as colloquiums at the University of St. Gallen (February 2018) and the Autonomous University of Barcelona (April 2018). We are very grateful to all participants at these events for many helpful suggestions which have improved our analyses. 


\section{Introduction}

In almost a century of empirical investigations the literature has accumulated a vast array of findings regarding the causes of non-voting. Strikingly, though, while we know who the non-voters are, and the reasons for their absenteeism, we know relatively little about what explains the cross-country differences in the turnout gap between rich and poor (Gallego, 2015; Amat \& Beramendi, 2020). We argue here that different welfare regimes trigger distinct mechanisms that explain the difference in rich-poor turnout gaps across democracies in the past decades. Our argument, rooted in the policy feedback literature (Pierson, 1993), is that welfare institutional frameworks have powerful and pervasive effects on citizens' political participation. These are exerted through signals about the importance and likely success of

participation, and through mobilization cues received from organizations empowered by these institutions.

We proceed as follows: In the subsequent section we offer a theoretical account of why welfare state characteristics impact the income-based gap in the propensity to vote. Following this, we employ Qualitative Comparative Analysis (QCA) to identify configurations of welfare state institutions that produce small gaps in turnout. This analysis is performed on 152 country-years, from 19 OECD members between 1960 and 2015. In a second half of the analysis we examine the micro-level mechanisms that link welfare regimes to lower turnout gaps. For this we use individual-level data on political mobilization, political efficacy, and political information, among others. We contrast citizens living in welfare regimes displaying low turnout gaps with those who do not live in such regimes, and expect that the former are more mobilized, politically efficacious, and informed. Our main finding is that mobilizing welfare regimes do indeed account for part of the differences in the income-based turnout gap across democracies: these trigger higher mobilization, feelings of efficacy, and/or political information among their citizens. In turn, these dynamics lead to lower turnout gaps. For the impact of supportive welfare regimes the individual-level evidence is weaker. The concluding section summarizes the results, outlines their implications, and sketches potential avenues of future inquiry.

\section{The Puzzle}

Why is it that some countries have very large gaps in turnout between income groups, while others have smaller disparities, or even none? The puzzle is evident in Figure 1, which displays the cross-case variation in income-based turnout inequality in 226 elections from 23 OECD democracies. The quantities plotted in the figure are obtained from country-by-country 
Figure 1: Histogram of income-based gap in turnout

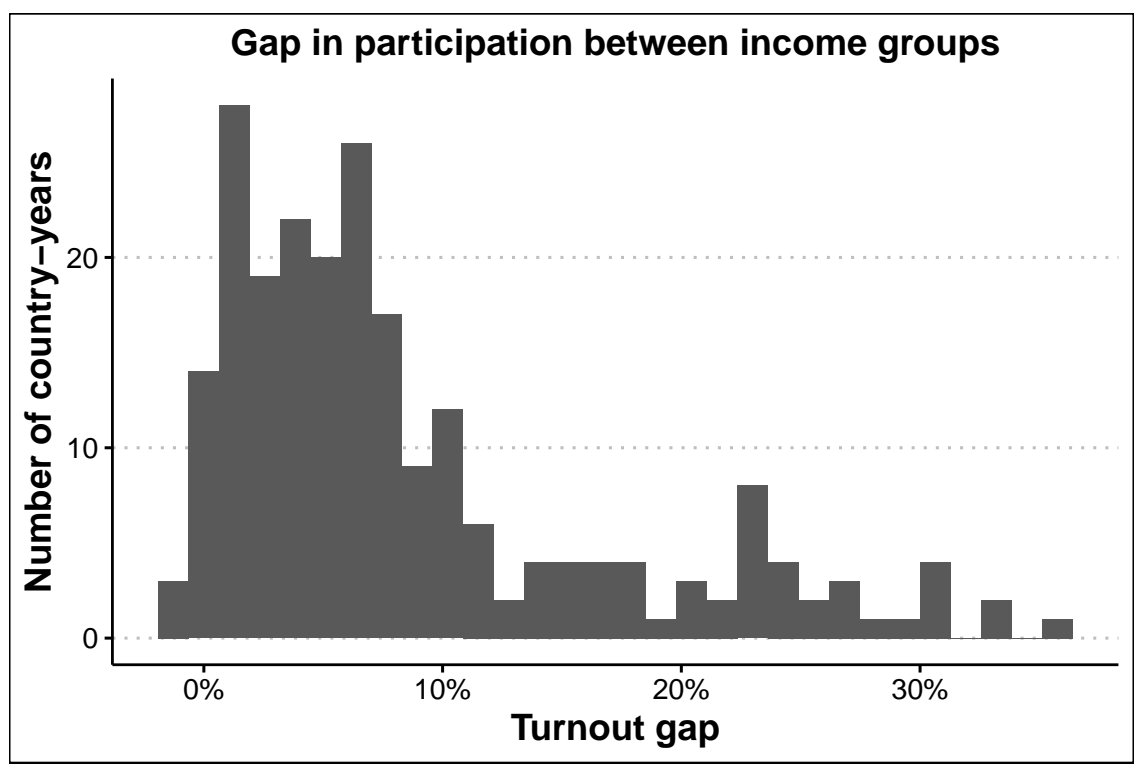

Note: Turnout gap computed as the difference between the probability of turnout of a voter in the third income tertile and that of a voter in the first income tertile, conditional on gender and age. $N=226$ elections.

regressions, where turnout is predicted with a simple set of socio-demographics: age, gender, and income. Based on these models, we compute the difference in the predicted probability of turnout between a respondent in the top income tertile and one in the bottom tertile, and plot them in Figure 1. ${ }^{1}$ In our sample income-based participatory inequality varies from -1.7 percent in Denmark in 1988 to about 35.3 percent in the US midterm election of 1966.

Though there are explanations for why such gaps might be different between countries (Gallego, 2015; Verba \& Nie, 1972), they cannot fully address why the gap goes from 1.1 in Germany in 1987 to 20.4 percent in 2009, or from 2.3 percent in the United Kingdom in 1966, to 23.3 percent in 2010. Recent accounts emphasizing the corrosive impact of income inequality (Solt, 2008), or the decline of associational networks (Armingeon \& Schädel, 2015), partly explain these longitudinal trends. Denmark, for example, has registered very small shifts in associational density or membership (Torpe, 2003) along with corresponding small fluctuations in the participation gap, from -0.45 percent in 1981 to 0.81 in 2007 . However, these accounts cannot explain the case of New Zealand, with larger declines in associational life (Vowles, 2004), but no corresponding changes in the turnout gap: 1.96 percent in 1981, and 1.12 in 2002. Neither does it account for the Canadian experience, where a visible increase in associational membership between 1981 and 2000 (Dekker \& Van Den Broek, 2005) has left the participation gap unchanged at 9.37 percent in 1984 and 9.45 percent in 2000 . We argue

\footnotetext{
${ }^{1}$ For a longer description of how these probabilities were obtained, please see Section 4.
} 
that one missing piece of the institutional puzzle is a country's welfare state structure. ${ }^{2}$

\section{Theories: Why poorer citizens (do not) vote less}

\subsection{Socio-economic inequality in political participation}

We currently know much more about the drivers of fluctuations in turnout levels (see, among others Abramson \& Aldrich, 1982; Franklin, 2004; Teixeira, 1987; Topf, 1995; Wattenberg, 2000), than we do about what impacts the gap in electoral participation between different socioeconomic groups (Amat \& Beramendi, 2020; Armingeon \& Schädel, 2015; Filetti \& Janmaat, 2018; Fraga, 2018; Gallego, 2010, 2015; Solt, 2008). Early analyses of the determinants of political participation clearly identified such disparities based on income and education in the United States (Verba \& Nie, 1972). Similar investigations in Western Europe, however, revealed no comparable gaps in participation forms other than voting (Topf, 1995). Both national and cross-national evidence suggests that such a gap in participation exists most advanced democracies (Gallego, 2008, 2010; Hakhverdian, van der Brug, \& de Vries, 2011; Quaranta, 2018), despite earlier evidence that it was limited to voting (Topf, 1995). Even more worrying are results that the turnout gap between educational has increased compared to its levels in the 1950s and 60s (Armingeon \& Schädel, 2015; Dassonneville \& Hooghe, 2017; Fraga, 2018).

Both trends are of concern in light of the theoretical (Lijphart, 1997) and empirical (Fellowes \& Rowe, 2004; Hajnal, 2010) association between unequal participation and skewed representation, and policies that disadvantage low-income citizens. Fellowes and Rowe (2004) find that in US states where high-income groups exhibit high turnout levels, welfare policies are stricter, less flexible and less generous than in other states (pp. 366-369). Although not universally valid (Kasara \& Suryanarayan, 2015), this "minimally participative" electorate in consolidated democracies usually comprises those with a low level of education and low income. No direct connection has been made to political representation so far ${ }^{3}$, though these are also the characteristics of voters who exert little influence over the shape of policies in a few advanced industrial democracies (Giger, Rosset, \& Bernauer, 2012; Gilens, 2005; Rosset, 2013).

\footnotetext{
${ }^{2}$ See also Torpe (2003) for an account of how the Danish welfare state is partly responsible for sustaining associational membership and activity.

${ }^{3}$ For gender, though, existing work has documented such a link (Dingler, Kroeber, \& Fortin-Rittberger, 2019).
} 


\subsection{Mechanisms leading to turnout gaps}

A range of theories account for why participatory disparities exist. The natural starting point are the resource endowments which underpin participatory acts: education, income, and time (H. E. Brady, Verba, \& Schlozman, 1995). These minimize the costs associated with the voting act, such as navigating registration requirements, or evaluating and synthesizing information about policies. With respect to education, the most consequential resource for voting, the evidence compiled by Gallego (2015) indeed suggests that a moderate to large gap exists in many of the countries covered by the Comparative Study of Electoral Systems (CSES). Resources can directly lower the costs of participating in politics, and indirectly influence participation by embedding individuals in social networks. Homophilic networks comprised of high SES individuals subsidize information costs by means of political discussion. At the same time, the network makes life harder for "shirkers" by increasing the social costs of abstaining (Abrams, Iversen, \& Soskice, 2010).

Even with such compounded disadvantages, though, lower SES individuals still vote, and almost achieve parity with their higher SES peers in Denmark, Spain or Belgium (Gallego, 2015). Part of the reason is that handicaps are compensated by the efforts of political parties (Amat \& Beramendi, 2020), unions (D'Art \& Turner, 2007) and NGOs (Gerber, Gruber, \& Hungerman, 2016) who evaluate and summarize political information and make a recommendation. Additionally, they provide logistical help - conveying information about polling locations - as well as a motivation: instilling a sense that election outcomes are important (Karp \& Banducci, 2004; Pattie \& Johnston, 2003). Fluctuations in the resources, organizational strength, and density of these associations over time and cross-nationally (Ebbinghaus \& Visser, 1999; Mair \& van Biezen, 2001) help explain why the participation gap between SES groups varies (Armingeon \& Schädel, 2015). Finally, individuals also turn out because they are motivated (Verba, Schlozman, \& Brady, 1995). Those who are more interested in political events (Rubenson, Blais, Fournier, Gidengil, \& Nevitte, 2004), are more informed (Weßels, 2018), more confident in their ability to participate in politics, and in the responsiveness of the political system (Karp \& Banducci, 2008), are more likely to participate in politics. To the extent that these psychological orientations are distributed unequally between socio-economic groups (Prior, 2019), involvement in politics will also be unequal.

In sum, the literature largely agrees that why citizens vote depends on the resources, networks, and motivation at their disposal, along with the mobilization efforts they are subjected to. Within each country, the second and third factors correlate with socio-economic status. Why, however, is the degree to which disadvantage translates into political inequality not constant across democracies? We claim that this is because the distribution of resources, networks, 
and motivation is shaped by country-level features, and specifically the characteristics of the welfare regime. We therefore now turn to macro-level determinants of turnout and then focus predominantly on welfare state types.

\subsection{Why the gap varies across countries}

Aggregate-level factors impact the participation gap by either (1) shaping the costs of voting, or (2) altering the motivation for turning out. Political institutions are typically placed in the first logic. A simple example of this is the sharp increase in the costs of (non-)voting achieved by compulsory voting laws (Lijphart, 1997). Where such laws are in effect, even with weak enforcement, the gap in turnout between SES groups is minimized. ${ }^{4}$ The electoral system type and ballot structure operate through a more complex mechanism. The electoral system influences the number of parties, and the types of post-election coalitions that can be formed (Cox, 1997). These, in turn, shape the amount of political information people require to feel competent in making an electoral decision. Whereas majoritarian systems with two opposing political parties are easily evaluated by even relatively unsophisticated voters, PR or mixed systems make higher cognitive demands. A similar logic operates for ballot structure, with open lists requiring considerable knowledge about political platforms and voting rules. The same conditions pose less of a hurdle for politically sophisticated voters - a dynamic which alters the turnout differential (Gallego, 2015, ch. 3).

Political polarization should also operate according to this logic: systems which offer a sharper set of alternatives, with clear consequences, make fewer cognitive demands on voters (Muñoz \& Meguid, 2021), and especially on those with lower political sophistication. Finally, cross-national variation in associational density shape the participation gap by reducing costs as well; NGOs provide members with transferable political skills, and frequently subsidize political information costs (Armingeon \& Schädel, 2015), which ought to be most valuable for voters with lower levels of education.

In the motivation logic we can place income inequality (Anderson \& Beramendi, 2012; Galbraith \& Hale, 2008; Solt, 2008, 2010). Sustained growth in inequality conveys to lower SES individuals that the political system is unresponsive to their expectations, regardless of the party in power (Goodin \& Dryzek, 1980). Higher SES individuals likely hold the opposing opinion, in light of the constant benefits they have experienced. A second pathway of transmission, of countervailing direction, works through the incentives which highly unequal contexts give parties (Amat \& Beramendi, 2020). With greater economic disparities, parties find it more cost-effective to use clientelistic appeals to mobilize lower-income voters, which

\footnotetext{
${ }^{4}$ Because of the strong effect of this institution Australia is excluded from our empirical analyses below.
} 
ought to reduce the participation gap (Matsubayashi \& Sakaiya, 2020).

We argue here that welfare state institutions consistently influence political participation, and that they operate through both logics. They strongly shape the resources individuals possess, alter their motivation (incentives) for participation, and mold the beliefs and political identities which can then be used by political actors for the purpose of mobilization (Pierson, 1993). We expand on this in the next section.

\subsection{How welfare regimes exert their influence}

While the SES model of H. E. Brady et al. (1995) links unequal participation to differences in resources, it does not also explain where discrepancies in resources (or motivation) come from. For this we find a plausible answer in the policy feedback literature, focusing on how policy characteristics drive political behavior by (1) shaping resources for participation, (2) altering psychological determinants of participation such as efficacy, and (3) shaping values, ideas and political identities, which make mobilization feasible (Campbell, 2012).

First, policies shape the resource endowments of individuals, thus altering the costs of participation. Prominent examples of this are pension systems, which guarantee a living income for retired workers, or social housing programs, or college grants (Mettler \& Welch, 2004). A second, and more complex, avenue of influence works through the feelings of subjective capability which drive an individual's political involvement. Policies such as pension systems, or social housing, confer rights and benefits on a group that, in this process, becomes a constituency which sees the policy as important to its livelihood, and thus increases its motivation to engage in political life. Policies can also influence citizens' sense of political efficacy or trust in institutions, if they are structured in a way that encourages participation and input by citizens, and that conveys a sense of entitlement and self-direction in benefit recipients (Soss, 1999); this is expected to spill over to the wider set of institutions. Finally, policies can also serve to shape political identities and suggest strategies of action for the mass citizenry (Pierson, 1993). Endowing a particular constituency with benefits also conveys to this group that they have joint interests. On the political elite side, such policies and the mass political awareness they generate suggest that a relevant cleavage could be activated by a willing entrepreneur.

Arguments like these, typically used for specific policies, can easily be deployed for a wider framework, such as welfare state institutions. In the process, we lose the fine-grained control over policy characteristics, as welfare states are a mix of programs. In exchange, we gain the ability to arrive at conclusions both in a cross-sectional and longitudinal framework, as we 
can assess differences in welfare regime characteristics over time and for multiple countries.

Using the example of resources, different welfare state types exhibit varying degrees of generosity (Scruggs, 2007). Relying on Esping-Andersen's (1990) typology, analyses find that social-democratic welfare states are the most generous, with high replacement rates for benefits, extensive coverage, and reduced barriers to access. If citizens recognize the importance of such sources of income for their well-being, and that governments can and frequently do amend these programs, we predict that residents of social-democratic welfare states are more engaged in politics than their peers in liberal welfare regimes. This attention-based argument is supplemented by a resource-based one: we expect that a more generous welfare regime reduces inequalities in political sophistication through the public provision of education. Turning to the psychological factors that underpin participation, the same claim can be made. Welfare state regimes are also distinct in the manner in which benefits are targeted toward the population (Esping-Andersen, 1990) and the sources for their financing (Bonoli, 1997). Under a Beveridgean model (as opposed to the Bismarckian one) coverage is universal, and the system is financed through general taxation, rather than employee and employer contributions (see Bonoli, 1997). This is expected to engender greater solidarity across subgroups in the citizenry, and to increase civic-mindedness - both of which are expected to reduce the participation gap between these subgroups. In the following empirical sections we identify which welfare regime leads to low participatory inequality and through which individual-level mechanisms it achieves this.

Though numerous welfare regime typologies exist in the literature (see, among others, Castles \& Mitchell, 1993; Esping-Andersen, 1990; Ferrera, 1996; Leibfried, 1993; Siaroff, 1994), our goal is to investigate the role of welfare regimes in mitigating the translation of social inequalities into political ones. This is a novel perspective and none of the existing typologies has been developed with this goal in mind. This is why we create our own country grouping instead, via Qualitative Comparative Analysis (QCA) (Ragin, 2008; Schneider \& Wagemann, 2012). The goal is to identify combinations of welfare state features that are necessary and/or sufficient for producing small discrepancies in participation between rich and poor citizens. Once these types are identified, they are used to group cases and to investigate the individual-level mechanisms through which they lead to low participatory inequality.

\section{Data, methods, and outcome to be explained}

The analyses we conduct are based on a custom-built data set, which merges selected variables from over 200 election studies carried out in 23 OECD countries (see Table 1 in Section 1 of 
the Online Appendix). The data set has been produced by manually merging national election surveys, relying on the unified merging scheme developed by the True European Voter (TEV) project (Schmitt, Önnudóttir, Teperoglou, \& Vegetti, 2013). A common recoding scheme was applied to all data sets, with the goal of maximizing coverage while at the same time making sure that selected questionnaire items are not wildly different from each other. ${ }^{5}$

The 'turnout gap' outcome is produced by country-level regressions of the probability to participate in elections on age, gender, and income. Income was split into approximately equal tertiles; depending on the income distribution and the original income scale used, the categories obtained diverged more or less from an equal split. From the 226 logistic regressions which we could run, we use the coefficient for income and computed the difference in the probability of voting of a high-income and a low-income respondent. These are the quantities plotted in Figure 1. For calibrating this data into membership in the outcome fuzzy set 'low participatory disparities' we use the direct method of calibration with the following qualitative anchors: $2 \%$ or lower turnout gap denotes full membership in the outcome set; $6 \%$ means "neither in nor out"; and cases with $15 \%$ or higher gap are fully out. Due to missing data patterns on our QCA conditions the final analysis sample consists of 152 election-years from 19 countries, ranging from 1960 to 2010.

We first use QCA to identify configurations of welfare state institutions and characteristics that are jointly sufficient for achieving a small participatory gap. We produce clusters of countries that look alike in terms of small participation gaps and their welfare configuration. Based on these country groups, we shift to the individual-level of analysis and investigate whether these country groupings exhibit the differences we would expect if our hypothesized mechanism linking welfare regimes to turnout gaps is at play. Over a range of such mechanisms - from education to rates of mobilization and political efficacy - we assess differences between citizens in these welfare regime clusters. While no mechanism test in isolation provides ground for bold conclusions, we compensate by running a large number of such tests over multiple data sources. If tests overwhelmingly point into the same direction, we have stronger grounds to infer that, indeed, our mechanisms lead to lower turnout gaps between rich and poor.

\section{A Qualitative Comparative Analysis (QCA) on income-based participatory inequalities}

In this section we describe the sets capturing the outcome 'low participatory disparities' and the welfare regime attributes, and then employ QCA to identify combinations of these welfare

\footnotetext{
${ }^{5}$ For details, please see Section 1 in the Online Appendix.
} 
regime attributes that are sufficient for low participatory disparities.

\subsection{Conditions and Outcome}

The outcome to be explained in our QCA is small participatory gaps (set label: LO_INEQ). ${ }^{6}$ We use four welfare state features as conditions. First, high welfare generosity (HIINDENXGEN), a set calibrated based on combined information on unemployment, sickness and pension benefits, obtained from the Comparative Welfare Entitlements Dataset (CWED) (Scruggs, 2007; Scruggs, Jahn, \& Kuitto, 2018). Second, high union strength (HIUNION), calibrated using a combined index of union density and union centralization. The former is obtained from the OECD/AIAS database on institutional characteristics of trade unions (ICTWSS), February 2021 version (OECD \& AIAS, 2021); the latter is taken from the Comparative Welfare States Dataset (CWD), January 2020 version (original variable name is unioncent) (D. Brady, Huber, \& Stephens, 2020). Third, high educational equality (HIEDU_EQUAL), calibrated based on V-DEM data, version 11.1 (original variable name is v2peedueq) (Coppedge et al., 2020). The index assesses to what extent quality basic education is guaranteed to all citizens, with values ranging from 0 (at least $75 \%$ of children receive low-quality education) to 4 (less than $5 \%$ receive low-quality education that does not allow them to exercise basic rights when adults). Finally, the set of high universalistic welfare policy (HIUNIV_BENEF) is calibrated based on V-DEM data (original variable name is v2dlunivl). This measures the extent to which welfare programs are universal as opposed to means-tested, on a scale ranging from 0 (there are very few welfare state policies) to 5 (almost all welfare policies are universal).

Table 1: Set calibration table

\begin{tabular}{lllccc}
\hline Set & Set label & Base variable & Fully out & Cross-over & Fully in \\
\hline High union density & HIUN_DENS & un_dens & 20 & 42 & 70 \\
High union centralization & HIUNIONCENT & unioncent & 1 & 2.2 & 4 \\
High welfare generosity & HINDEX_GEN & index_gen & 23 & 29 & 38 \\
High educational equality & HIEDU_EQUAL & edu_equal & 1 & 2.3 & 3.1 \\
Universalistic welfare benefits & HIUNIV_BENEF & univ_benef & 0.75 & 1.3 & 2.7 \\
Low income-based participatory & LO_INEQ & diffInc & 0.15 & 0.06 & 0.02 \\
inequality (outcome set) & & & & \\
High union strength & HIUNION & HIUN_DENS + HIUNIONCENT & \\
\hline
\end{tabular}

Note: $+=$ logical OR.

The qualitative anchors used for calibrating the outcome and condition sets can be found in Table 1. Sensitivity ranges and robustness tests (Oana \& Schneider, 2021) for these anchors

\footnotetext{
${ }^{6}$ For calibrating our outcome sets, we use the point estimates shown in Figure 1, thus ignoring the uncertainty around these estimates. Future research could capture those with second-order fuzzy sets (Mendel \& Korjani, 2018).
} 
are reported in Section 7 of the Online Appendix.

\subsection{Analysis of small participatory disparities}

Set-theoretic analyses distinguish between two forms of set relations: conditions can be a superset or a subset of the outcome. If the former, there is empirical support for considering the condition as necessary for the occurrence of the outcome. If the latter, there is empirical support for the condition being sufficient for the occurrence of the outcome. Investigations usually start with an analysis of necessity, followed by an analysis of sufficiency (Schneider \& Wagemann, 2012).

The analysis of necessity for outcome small participatory inequality reveals that the disjunction of high educational equality or high universal benefits passes the empirical criteria for being a non-trivial superset of the outcome. We interpret these as so-called SUIN conditions (Mahoney, Kimball, \& Koivu, 2009): functional equivalents of a higher-order concept that we label 'high access equality to welfare benefits' $(Z$ ) (see Expression 1). In other words, high access equality to welfare benefits is needed in order to achieve small participatory gaps between income groups, irrespective of the specific welfare regime types identified in the following analysis of sufficiency. ${ }^{7}$ Access quality Z materializes either through high educational equality (HIEDU_EQUAL) or high universal benefits (HIUNIV_BENEF).

$$
\left\{\begin{array}{l}
Z \leftarrow L O \_I N E Q \\
Z=H I U N I V \_B E N E F+H I E D U_{-} E Q U A L
\end{array}\right.
$$

The analysis of sufficiency proceeds as follows. We obtain the truth table displayed in Section 3 of the Online Appendix (Table 2 on page 10). With four conditions, the truth table has $2^{4}=16$ rows. Our 152 country-election observations populate 13 rows, leaving three logical remainder rows (not displayed in the table). Rows with a raw consistency (column consistency) higher than 0.7, PRI (column PRI) higher than 0.55, and with at least two cases being a member (column $\mathbf{n}$ ) have been coded as being sufficient for the outcome and are thus included in the logical minimization procedure $(O U T=1)$. Rows that contain enough empirical evidence but do not pass the consistency or PRI threshold are excluded from the logical minimization $(O U T=0)$. Logical remainder rows $(O U T=?)$ are included if and when they represent simplifying assumptions (Ragin, 2008, ch. 9) that are tenable (Schneider \& Wagemann, 2012,

\footnotetext{
${ }^{7}$ Another disjunction passes the thresholds consistency $=.9$, coverage $=.6$, and ron $=0.5$ : high educational equality or high welfare generosity (see Online Appendix, Section 4, Table 3). Since we fail to identify the higher-order concept of which these two sets are functional equivalents, we abstain from interpreting this disjunction as necessary for the outcome low participatory inequality (Schneider, 2018).
} 
ch. 8). In order to achieve that at least one of our two necessary SUIN conditions is contained in each sufficient term, we employ Enhanced Standard Analysis (Schneider \& Wagemann, 2012)..$^{8}$

The enhanced parsimonious solution displayed in Table 2 on page 11 reveals four sufficient terms. Each of them contains at least one of the two necessary SUIN conditions. Jointly they cover, or explain, 82 percent of the the cases' membership in outcome 'low participatory gap' (raw coverage: 0.822). ${ }^{9}$ Two of the four sufficient terms identify the presence of high union strength (HIUNION) combined with either high educational equality (HIEDU_EQUAL) or high universal benefits (HIUNIV_BENEF). Both terms cover the highest share of cases (raw coverage over 0.6), which means that membership in either of these assemblages of welfare state institutions can explain almost two-thirds of the outcome. Because of the explicit presence of strong unions, not required in the other two sufficient terms, we label this welfare regime mobilizing. We hypothesize that disadvantaged citizens in this welfare regime are more mobilized, which, in turn, accounts for the smaller turnout gap between rich and poor. We test for this mechanism in Section 6.

Table 2: Parsimonious solution for 'low turnout gaps' outcome

\begin{tabular}{|c|c|c|c|c|c|}
\hline $\begin{array}{l}\text { Welfare } \\
\text { regime type }\end{array}$ & Solution terms & Consistency & PRI & $\begin{array}{l}\text { Raw } \\
\text { coverage }\end{array}$ & $\begin{array}{l}\text { Unique } \\
\text { coverage }\end{array}$ \\
\hline Mobilizing & HIUNION *HIEDU_EQUAL & 0.689 & 0.614 & 0.610 & 0.052 \\
\hline Mobilizing & HIUNION $*$ HIUNIV_BENEF & 0.720 & 0.646 & 0.606 & 0.067 \\
\hline - & HIINDEX_GEN $*$ HIEDU_EQUAL $* \sim$ HIUNIV_BENEF & 0.774 & 0.633 & 0.177 & 0.096 \\
\hline Supportive & HIINDEX_GEN * HIEDU_EQUAL * HIUNIV_BENEF & 0.728 & 0.640 & 0.555 & 0.032 \\
\hline \multicolumn{2}{|c|}{ Overall solution } & 0.692 & 0.612 & 0.822 & \\
\hline
\end{tabular}

Note: Directional expectations: for all four conditions, presence is expected to be conducive for the low turnout gaps outcome.

Another sufficient term combines high educational equality (HIEDU_EQUAL) with the presence of both high welfare generosity (HIINDEX_GEN) and of high universal benefits (HIUNIV_BENF). We interpret this as a higher-order welfare regime type that we label supportive. Disadvantaged citizens in this welfare regime are more likely to be supported in terms of resources needed for political participation (financial, time, cognitive skills etc.), which, we propose, explains the lower turnout gaps in these countries. A more detailed elaboration of which mechanisms are

\footnotetext{
${ }^{8}$ One of the three logical remainder rows is therefore blocked from being included into the logical minimization because it would amount to an untenable assumption as it contains the negation of our necessary disjunction.

${ }^{9}$ Since this solution is obtained on data pooled over several decades, development periods, and election cycles, we tested whether the same QCA solution formula adequately describes the data in specific decades, periods, and election cycles. We find that it does and therefore conclude that pooling does not distort the results. For more details on this cluster diagnostics (Oana, Schneider, \& Thomann, 2021, chapter 5.3), please see Section 6 in the Online Appendix.
} 
triggered in which welfare regime type are provided in the following section (see also Figure 2 on page 15). A fourth sufficient term combines high educational equality with the absence of high welfare generosity and of high universal benefits. This term exclusively applies to New Zealand over the period from the 1980s to the early 2000s. Its raw coverage is therefore by far the lowest, at 0.177. Conceptually, it cannot be interpreted as either supportive or mobilizing, which is why it is excluded from the subsequent individual-level analysis. ${ }^{10}$

Table 3 on page 14 shows how all our cases are classified based on the QCA solution in Table 2. This classification stems from the set-theoretic multi-method (SMMR) literature, a framework for combining QCA with within-case analyses (Schneider \& Rohlfing, 2013; Oana et al., 2021, chap. 6.3). Typical cases for a mobilizing or supportive welfare regime are those that are members of one of these regime types and of the outcome small participatory inequality. Uniquely typical are those cases that are typical for only one regime type but not both. We expect to see the hypothesized individual-level mechanisms in action in this group of cases, which we empirically test for in the following section. The grouping of typical cases, while largely in line with intuition, does not fully coincide with that of existing welfare regime typologies. For instance, our mobilizing regimes match fairly well the social-democratic welfare state type (Esping-Andersen, 1990), with Denmark, Norway, Finland, Netherlands, or Sweden as typical cases. However, this group also includes New Zealand, which is a hybrid case in Esping-Andersen's typology, as well as Italy, which is usually included in the 'Southern' model (Ferrera, 1996). The supportive regime type includes a number of countries typically found in Esping-Andersen's social-democratic type (Denmark, Finland, Sweden, and Norway), but also Belgium and Netherlands - which have distinct elements of the conservative type in their institutional design-, as well as Spain (another example of the 'Southern' model).

Deviant consistency cases are members of a welfare regime, but not of the outcome. They therefore reduce the empirical consistency of the claim that a welfare regime is sufficient for low participatory inequality. Austria in 2008 is an example of a deviant consistency case for the mobilizing welfare regime. Deviant coverage cases, in turn, are members of the outcome to be explained, but not of any of the explanations found in our QCA solution. Cases such as Canada in 1974 or Japan in 1990 remain unexplained cases of low participatory inequality by the QCA model. Finally, globally uncovered cases are neither members of the outcome, nor of any of our four sufficient terms. This group is dominated by cases from the US, but also features several years from Great Britain, Canada, Germany, or France. As such, they neither support nor contradict our finding that mobilizing or supportive welfare regimes are

\footnotetext{
${ }^{10} \mathrm{~A}$ few New Zealand country-years are nevertheless included in the following mechanism analysis because they are typical for other sufficient terms.
} 
sufficient for low participatory inequality. However, they do play the role of contrast group in our individual-level analysis on the mechanisms in the next section.

\section{Analysis of individual-level mechanisms linking welfare regime types with participatory inequalities}

So far our analysis has been at the aggregate-level: it has identified combinations of conditions (factors) which are associated with small participatory disparities. In this second part of the analysis we show how these cross-case effects are transmitted through a series of individuallevel mechanisms. More specifically, we contrast citizens living in one of our two welfare regime types with citizens who live in the set of globally uncovered cases revealed by our analysis: those with a not small participation gap and which are not members of either a mobilizing or supportive welfare regime. These contrasts are structured around the mechanisms that we claim drive the participation gap differences between mobilizing and supportive welfare regimes, on the one hand, and not-mobilizing and not-supportive regimes, on the other.

Figure 2 provides a graphical depiction of our cross-case-within-case analytic setup and argument. At the cross-case level, our QCA has identified the two welfare regimes types that are sufficient for low participatory gaps. In the following within-case analyses we investigate whether each of our welfare regime types triggers individual-level mechanisms that, in turn, are associated with low turnout gaps. Some of these mechanisms are expected to be triggered by both welfare regime types (political information and political efficacy), others only by one of the two (e.g. low gaps in political mobilization by the mobilizing regime or low educational gaps by the supportive regime). ${ }^{11}$

\subsection{Hypotheses}

Starting with the mobilizing/neither-mobilizing-nor-supportive contrast, we should see higher rates of party mobilization in mobilizing regimes, as proxied by contact rates of lower- and higher-income citizens. We also posit that mobilizing regimes display smaller gaps in political information and efficacy between income groups than their counterparts. Finally, based on the mobilization differential, we ought to observe a narrower difference in mobilizing regimes between income groups in whether they feel closer toward specific political parties. The following hypotheses are generated:

\footnotetext{
${ }^{11}$ Our analytic framework is inspired by that of set-theoretic multi-method research (SMMR) (Schneider \& Rohlfing, 2013; Oana et al., 2021, chap. 6.3), a combination of set-theoretic analyses at both the cross-case and the within-case level. In our framework only the cross-case analysis is cast in terms of set relations via our QCA, whereas the within-case analysis consists of standard quantitative correlational analyses.
} 


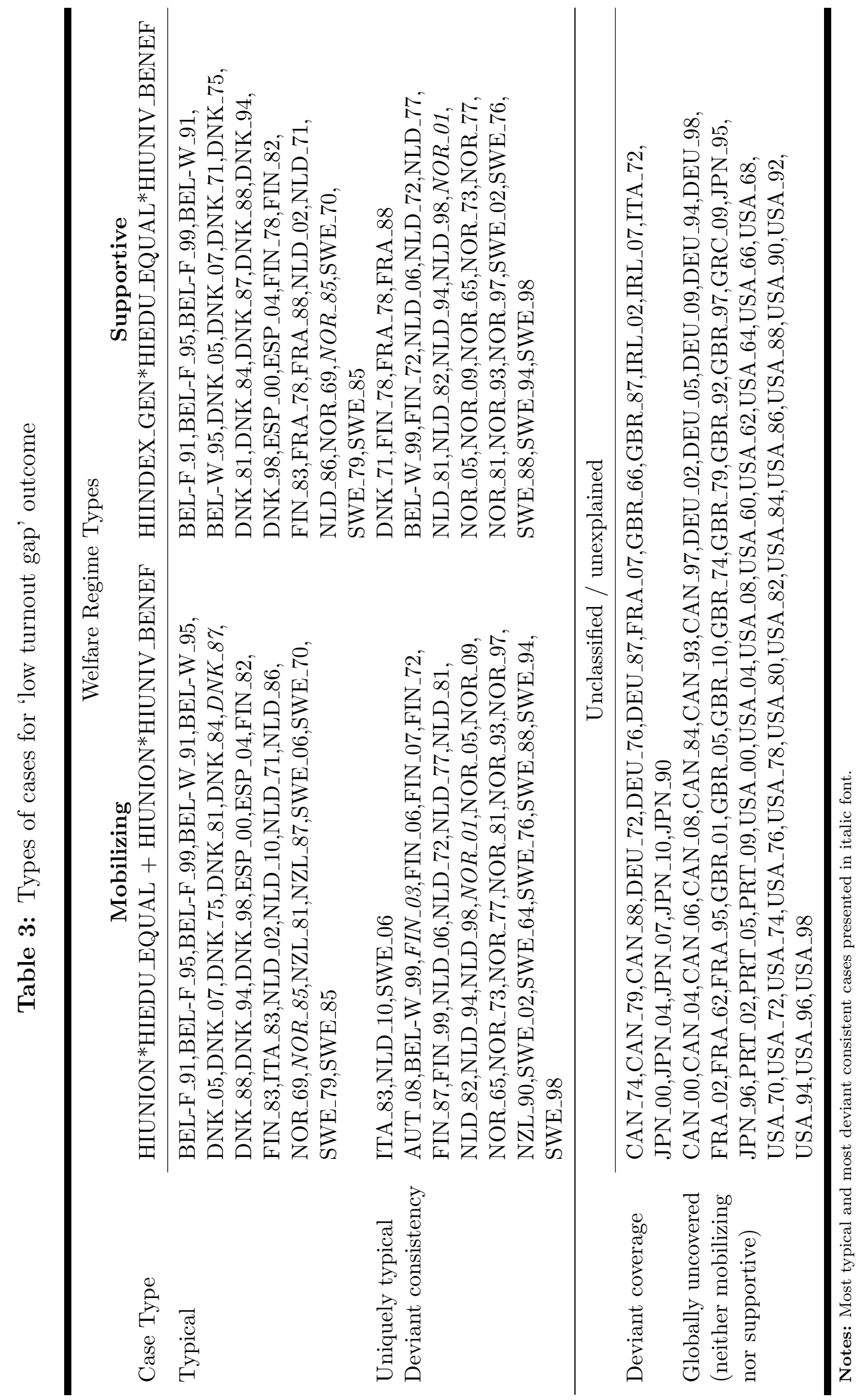


Figure 2: Logic for mechanism investigation

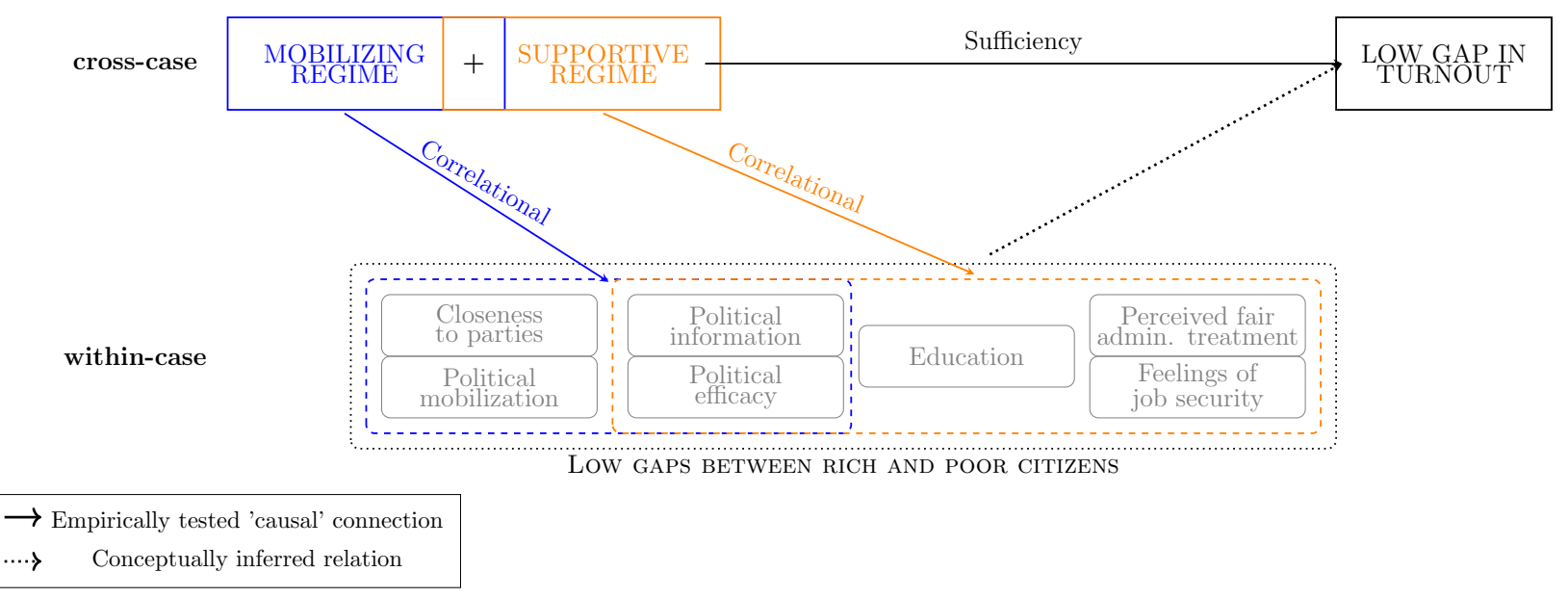

Note: The solution for the mobilizing type is HIUNION * (HIEDU_EQUAL + HIUNIV_BENEF). The solution for the supportive type is HIINDEX_GEN * HIEDU_EQUAL * HIUNIV_BENEF.

Hypothesis $\mathbf{1}(\mathbf{H} 1)$ : The gap between rich and poor citizens is smaller in mobilizing welfare regimes than in non-mobilizing regimes in terms of (H1a) mobilization; (H1b) feeling close to political parties; $(\boldsymbol{H 1} \boldsymbol{c})$ political information, and $(\boldsymbol{H} \mathbf{1 d})$ political efficacy.

On the supportive/neither-supportive-nor-mobilizing side our QCA investigation pointed to supportive systems' ability to reduce the divergence in participation-relevant resources between income groups, most importantly education. These systems should also do a better job at protecting these resources (especially income) from losses incurred due to job termination. We therefore anticipate a lower gap in educational attainment between income groups in supportive regimes compared to non-supportive ones. We also expect generous welfare benefits to reduce the inter-group gap in concern over the possibility of unemployment. Turning to attitudes, just as for mobilizing/non-mobilizing systems, we expect the reduced divergence in education to produce a narrower gap in political efficacy and in political information. Finally, we check whether part of the explanation for varying rates of turnout resides in citizens' experiences with bureaucratic agencies, which reinforce the belief that government is receptive to citizens' inputs. We believe supportive regimes should display narrower gaps in beliefs about the civil service being fair and impartial, compared to non-supportive systems. Formulated as hypotheses:

Hypothesis $\mathbf{2}(\mathbf{H} 2)$ : The gap between rich and poor citizens is smaller in supportive welfare regimes than in non-supportive regimes in terms of (H2a) education; (H2b) political information; (H2c) political efficacy; (H2d) feeling of job security; and (H2e) feelings of being treated fairly by the bureaucracy. 
To test our first batch of hypotheses we contrast citizens that only live in mobilizing regimes (i.e. in uniquely covered typical cases) with citizens that live in neither-supportive-nor-mobilizing ones (i.e. globally uncovered individually irrelevant cases). For the second set of hypotheses we contrast citizens living in only this type with those residing in neither-supportive-normobilizing regimes (see Table 3).

Lack of detailed information on most mechanisms outlined above makes it impossible to cover the entire temporal spectrum with detailed information at the individual level. The cross-national survey programs we rely on cannot cover cases going too far back in time, e.g. the US in 1960; the individual-level surveys are also frequently run in years that do not match with the ones in our QCA analysis. To address this, we implement a 5-year selection window on either side of a QCA case. As long as we have individual-level information on a mechanism within five years of our QCA country-year, we use it in our mechanism analyses. We present results from nine surveys: waves 1-3 of the Comparative Study of Electoral Systems (CSES), waves 1-5 of the European Social Survey (ESS), and the 4th round of the Role of Government module from the International Social Survey Program (ISSP).

We use many specifications to test whether the income gap is smaller in either mobilizing or supportive regimes than in their counterparts in the "globally uncovered" cluster: linear models, logistic regression, and ordinal logit models. At their core, however, lies a standard form expressed in Equation 2 for a linear model:

$$
Y_{i}=\beta_{0}+\beta_{1} \text { Regime }_{i}+\beta_{2} \text { IncomeMid }_{i}+\beta_{3} \text { IncomeHigh }_{i}+\beta_{4} \text { Regime }_{i} \text { IncomeHigh }_{i}+\epsilon_{i}
$$

The response variable consists of an examined mechanism, such as political efficacy, or

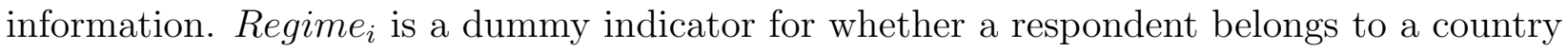
from the mobilizing (supportive) cluster, or not. The next two predictors are dummy indicators for whether the individual is in the second or third tertile of income. The estimate of interest, however, is $\beta_{4}$. This assesses how the gap between high- and low-earners changes when comparing individuals from the "globally uncovered" cluster to those in the mobilizing (supportive) one. Our hypotheses are confirmed if all $\beta_{4}$ are consistently negative and statistically significant. This indicates that the gap in the outcome in mobilizing (supportive) regimes is smaller than the corresponding gap in the "globally uncovered" cluster. Figure 3 presents three potential results, or ideal types. The first panel depicts the scenario we just described, with all $\beta_{4}$ s negative and most statistically significant; we consider this a confirmation of our hypothesis. The middle panel, in turn, presents a mixed bag of positive and negative estimates, leading to an inconclusive verdict. The last panel depicts tests that 
Figure 3: Stylized depiction of potential configurations of results in the mechanism analysis

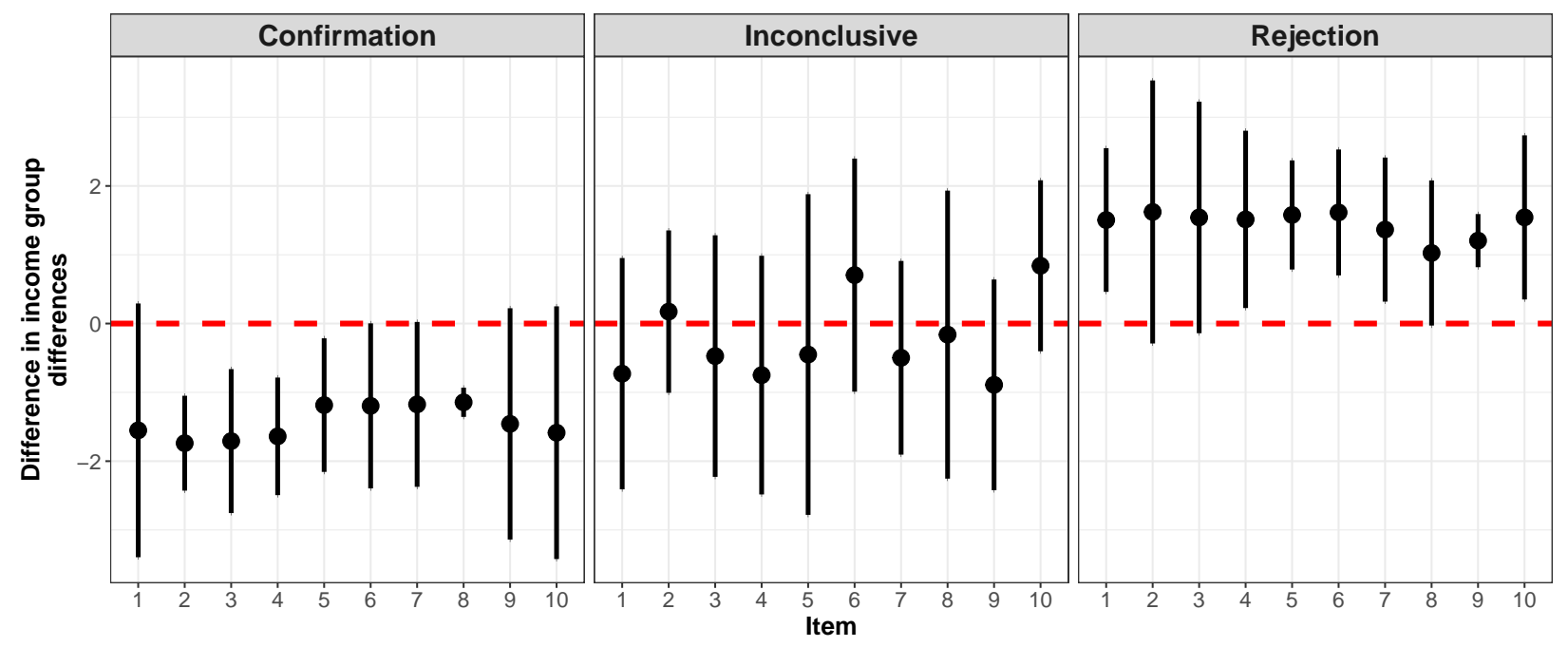

yield positive estimates, which classifies this as a clear rejection of our propositions.

\subsection{Results of mechanisms analyses for mobilizing regimes}

Figure 4 compares mobilizing with non-mobilizing regimes. Each mechanism is presented in its own section of the plot, delimited with red vertical lines. As a "practice run", the first section of the plot visualizes the political participation mechanism. Here we examine whether the turnout disparity uncovered by the QCA analysis is also present for non-electoral forms of participation, such as contacting a politician, or signing a petition. For each of the five surveys in this section we construct an additive index of the number of such acts respondents engaged in. The evidence confirms our hunch. In all five surveys the participation gap is narrower in the mobilizing cluster than the non-mobilizing one; in four out of the five, this difference is statistically significant. In visual terms, all $\beta_{4}$ and almost all the confidence intervals are below the line of no effect. These are the steps we follow when examining all subsequent plot sections, and we conclude from this examination that our first hypothesis is largely confirmed.

In the next two panels we probe political mobilization. Though an item about union contacts during the campaign is not available, we know whether the respondent is a union member or not. ${ }^{12}$ We find, in eight out of nine tests, that the income-based membership gap is lower in mobilizing regimes than non-mobilizing ones, and that this difference is statistically significant. The only exception is wave 2 of the CSES, though even here, levels of union membership are

\footnotetext{
${ }^{12}$ We assume that union membership produces exposure to subtle cues and direct encouragement regarding turning out to vote and the vote choice.
} 


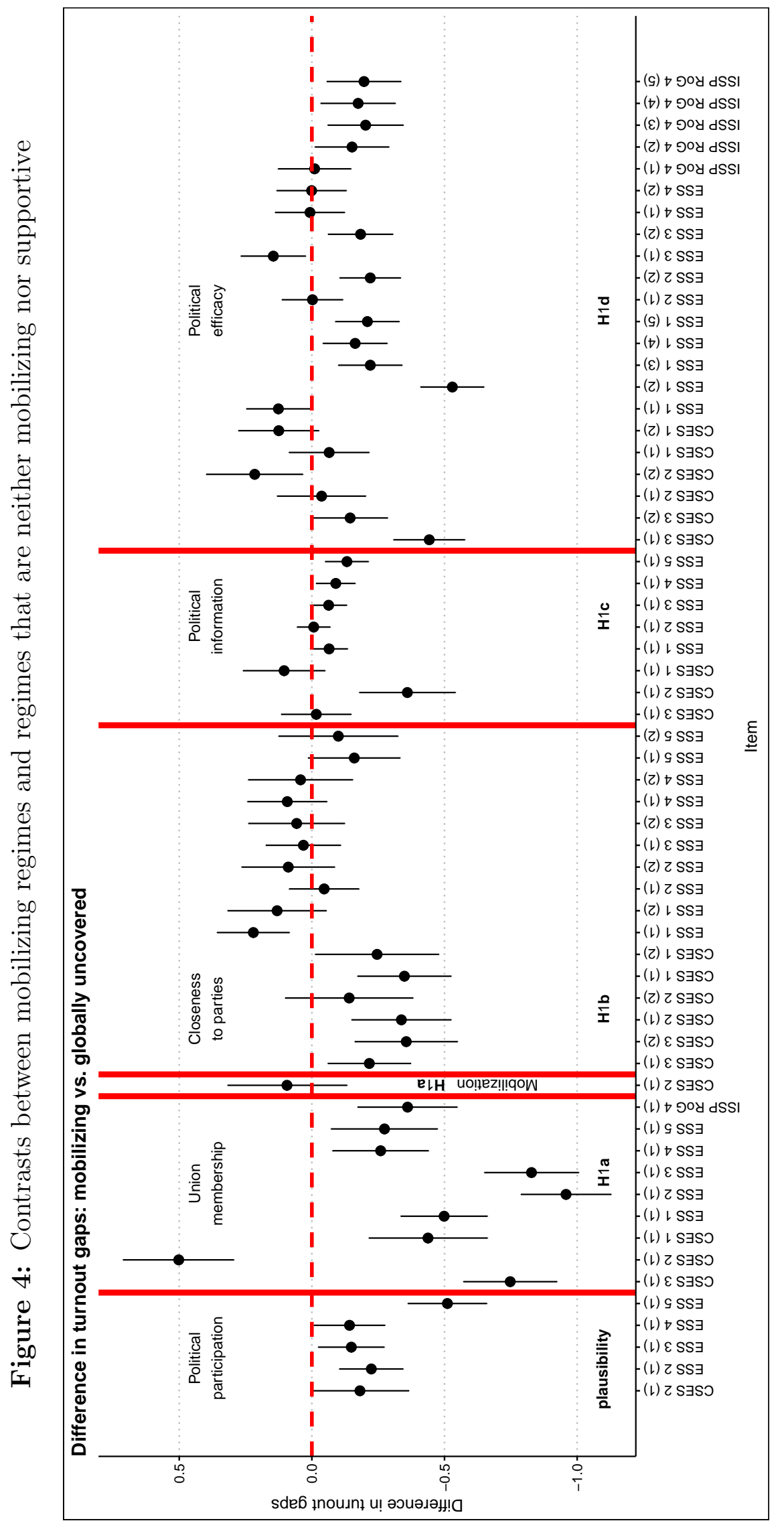

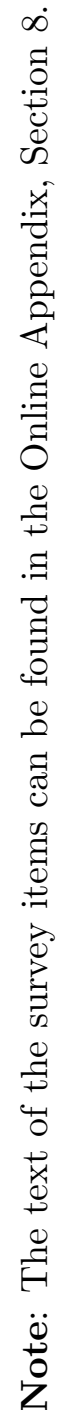


higher in mobilizing regimes: low-income citizens' membership rate in mobilizing regimes is on average $22.3 \%$ - and thus larger than even the rate for high-income citizens in non-mobilizing regimes $(21.4 \%)$. This high membership rate produces a ceiling effect in terms of turnout rates. Wave 2 of CSES also contains an item that speaks more directly to campaign activities: whether the respondent was contacted by a candidate or party during the campaign. Here we find no support for our hypothesis, as the third section in Figure 4 shows. Even so, given the overwhelming support received by the union membership proxy, we qualify this hypothesis (H1a) as confirmed.

We move quicker through the rest of Figure 4. The evidence for the closeness to political parties mechanism is mixed. Out of 16 tests, only slightly more than half (9) point in the expected direction; of these, five are statistically significant. Although only one of the seven estimates that disconfirm our hypothesis is statistically significant (wave 1 of ESS), we conclude that closeness to parties mechanism $(\mathbf{H 1} \mathbf{b})$ is weakly supported. We are more confident for our political information pathway. Of the eight conducted tests, seven are in the expected negative direction, and of these three are significant. The evidence therefore provides more grounds for concluding there is an effect through the information mechanism (H1c). Finally, we collate 22 tests for political efficacy. Overall, we find the hypothesized negative estimate in 16 tests; in 12 of these this is also statistically significant. The evidence goes against our expectations in only three cases (wave 2 of CSES, and waves 1 and 3 of ESS). We qualify this as medium-strong support for our efficacy pathway (H1d). We thus see that mobilizing regimes raise overall levels of efficacy more effectively. Together with political information, and mobilization done by labor unions, this last mechanism finds the most consistent support in the data.

Grasping the magnitude of uncovered effects is challenging, as Figure 4 displays raw regression coefficients. To address this we translate a few estimates from the figure into raw predicted probabilities or level of the outcome - the results are in Section 9 of the Online Appendix (Figure 2). Overall, except for closeness to parties, we see small effect sizes for each mechanism, though naturally their cumulative effect might be more substantive.

\subsection{Results for supportive regimes}

We follow the same process of reasoning for the tests for mechanisms operating in supportive regimes. Figure 5 on page 21 shows the findings, which contrast citizens in supportive welfare regimes and those from neither-supportive-nor-mobilizing regimes (our "globally uncovered" cluster). The plot is arranged in familiar panels, based on the specific mechanism being probed. Overall, we find much weaker support for this group; virtually none of our hypothesized 
mechanisms find unambiguous support.

For education, out of 11 tests eight produce the expected negative estimate, signaling that the educational achievement gap is lower in supportive regimes than their non-supportive counterparts. Of these eight only four are statistically significant; though none of the positive estimates counter to our expectation reach statistical significance, we conclude that the evidence in support of this mechanism $(\mathbf{H 2 a})$ is inconclusive. Even less support is found for political information. Of the six tests three produce the hypothesized negative estimates, but only one is statistically significant. We conclude that our presumed mechanism of transmission (H2b) is not responsible for the differences in turnout gaps we observe. For political efficacy the evidence is mixed as well, though leaning more in favor of this mechanism. Out of 20 tests 14 reveal the negative estimate we expect; of these, eight are also significant. Though the evidence does not uniformly point in the same direction, there is more support for the political efficacy pathway $(\mathbf{H 2 c})$ than against. The remaining pathways $(\mathbf{H 2 d}$ and $\mathbf{H 2 e})$ find no confirmation, though we can only run a few tests: one for concern about future unemployment, and two for perceptions of fair bureaucratic treatment. Neither test passes the threshold for significance, and we conclude there is no support for this mechanism. As for mobilizing regimes, we present in Section 9 of the Online Appendix (Figure 3) an illustration of the effect sizes we uncover, though the evidence uniformly points to small magnitude effects for education and political efficacy.

\section{Discussion and concluding remarks}

We have argued, and empirically shown, that welfare state characteristics are systematically linked to variations in the income-based turnout gap in a number of long-standing OECD members. A QCA analysis has revealed two types of welfare regimes conducive for small turnout gaps: mobilizing and supportive. Using micro-level data we then probed the mechanisms through which these two welfare regime types exert their influence. Most mechanism tests point in the expected direction for our mobilizing/non-mobilizing contrast. In mobilizing welfare states, rich and poor citizens are more similar than in non-mobilizing regimes when it comes to political mobilization (proxied by union membership), political information, and feelings of internal and external political efficacy. For our supportive/non-supportive contrast, on the other hand, our expectations are largely not met. Rich and poor citizens in supportive welfare regimes are not more alike than in non-supportive regimes in educational achievement, political information, concern about future unemployment spells, or feeling mistreated by the bureaucracy. The only area where observed differences matched our expectations was

political efficacy, where income-based gaps in supportive regimes were indeed smaller than in 


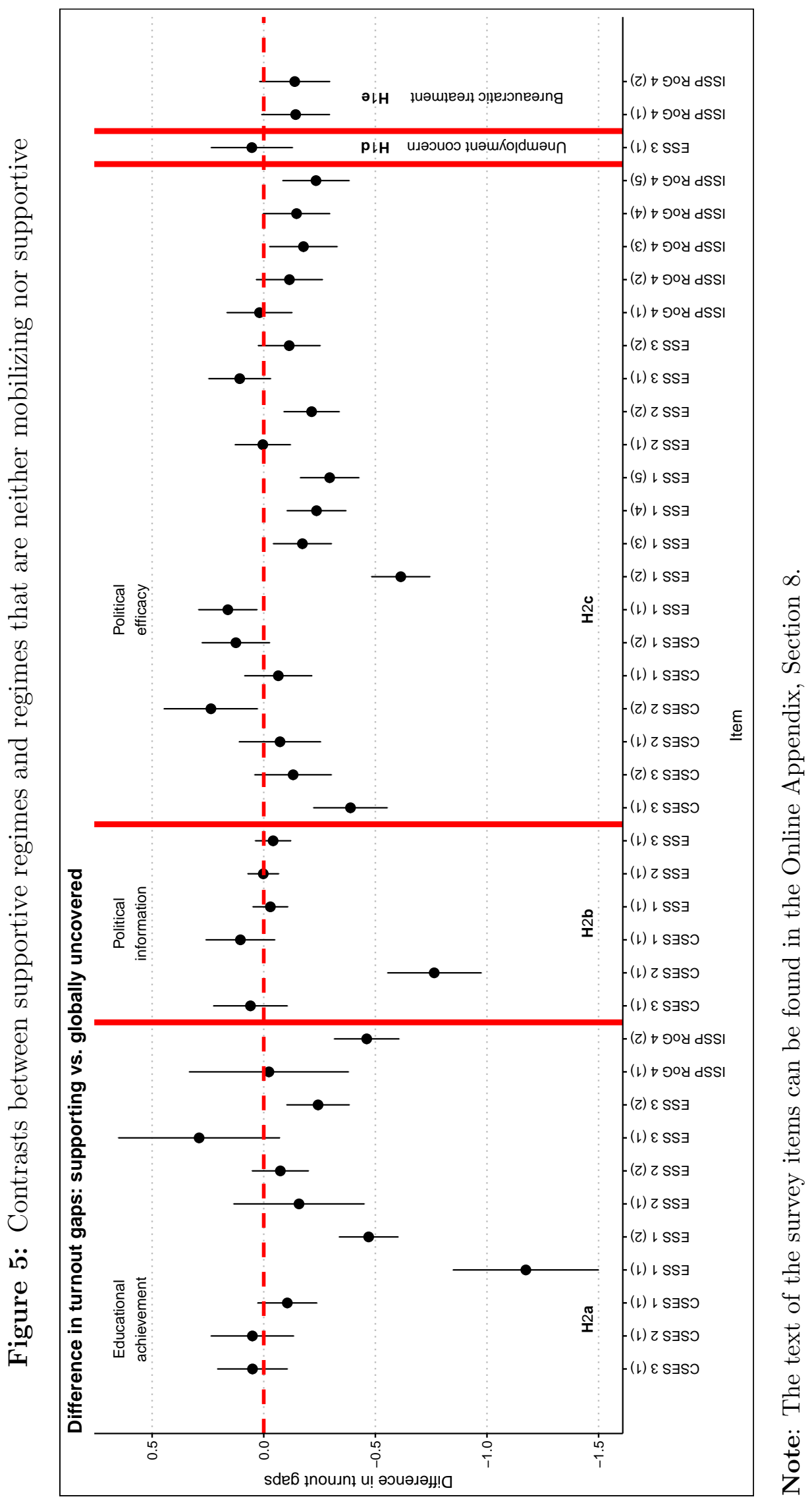


non-supportive ones.

Ours is partly a story about motivation to participate, and how the unequal distribution of this psychological orientation produces unequal turnout. More than two decades after the insights of H. E. Brady et al. (1995), though, this has become a pedestrian plot. We unravel here a more elaborate narrative about where this disparity in motivation comes from: welfare state characteristics. Union strength and welfare generosity are associated with variations in rates of mobilization, and in disparities in political information and political efficacy; in conjunction, these lead to smaller disparities in participation. We partly also emphasize the importance of mobilization and resources. Existing accounts prominently feature these two factors (Amat \& Beramendi, 2020; Gallego, 2015), but cannot also account for the background institutional framework that generates inequality or information disparities beyond those caused by media regimes. Our analysis here thus complements these accounts.

The implications of these results are manifold. For one, there are clearly multiple pathways to the same outcome of low participatory gaps. We identify a mobilization route, through union appeals, but find less evidence for a supportive route, operating through resources. Other paths must exist, as the cases left unexplained in our model suggest. A more fundamental insight refers to how we study participation itself: while a focus on resources is still crucial, examining discrepancies in participation also requires that we turn to how the wider social system responds to gaps in resources. Whether unequal resources are compensated for by targeting mobilization appeals at those who are least politically engaged can impact whether we see turnout differences between income groups. Finally, our macro-micro focus offers a framing for a number of insights into the role of emotions for participation, and particularly anxiety. This has been shown to negatively impact participation (Valentino, Brader, Groenendyk, Gregorowicz, \& Hutchings, 2011), though we lack a connecting story about the origins of differences between sub-groups in susceptibility to anxiety. We believe our framework can provide this, by linking the insurance function of welfare states to feelings of anxiety in the face of economic change, and further to turnout disparities. Such a macro-micro-macro linkage offers an exciting set of questions to pursue.

Further work naturally awaits. The priority must be a better understanding of the mechanisms through which our supportive welfare regime operates. We have found little support for educational achievement, or perceptions of bureaucratic impartiality. How then do these regimes achieve small gaps in participation between income groups? Our welfare categories also require improvement; a subsequent step would be to move from broad clusters of institutional characteristics to specific arrangements, to pinpoint the institutions with the greatest amount of influence over the participation gap. Finally, the issue of gaps in the attitudinal foundations 
of participation is still open. Our preliminary investigations have revealed partial support for an efficacy-based argument. Further work should cast a wider net, perhaps with a view to trust in institutions or in politicians.

Given the complexity of modern welfare states, and the multitude of transmission pathways, the magnitude of the task is understandably daunting. Attempting it is crucial though, as unequal turnout can drive unequal representation (Lijphart, 1997), with vast consequences over the lives of the more vulnerable categories of citizens in our societies. 


\section{References}

Abrams, S., Iversen, T., \& Soskice, D. (2010). Informal Social Networks and Rational Voting. British Journal of Political Science, 41(02), 229-257.

Abramson, P. R., \& Aldrich, J. H. (1982). The Decline of Electoral Participation in America. The American Political Science Review, 76 (3), 502-521.

Amat, F., \& Beramendi, P. (2020). Democracy under High Inequality: Capacity, Spending, and Participation. The Journal of Politics, 82(3), 859-878.

Anderson, C. J., \& Beramendi, P. (2012). Left Parties, Poor Voters, and Electoral Participation in Advanced Industrial Societies. Comparative Political Studies, 45(6), 714-746.

Armingeon, K., \& Schädel, L. (2015). Social Inequality in Political Participation: The Dark Sides of Individualisation. West European Politics, 38(1), 1-27.

Bonoli, G. (1997). Classifying Welfare States: a Two-dimension Approach. Journal of Social Policy, 26(3), 351-372.

Brady, D., Huber, E., \& Stephens, J. D. (2020). Comparative Welfare States Data Set. Chapel Hill, NC: University of North Carolina and WZB Berlin Social Science Center. Retrieved from https://www.lisdatacenter.org/news-and-events/ comparative-welfare-states-dataset-2020/

Brady, H. E., Verba, S., \& Schlozman, K. L. (1995). Beyond SES: A Resource Model of Political Participation. The American Political Science Review, 89(2), 271-294.

Campbell, A. L. (2012). Policy Makes Mass Politics. Annual Review of Political Science, 15, 333-351.

Castles, F. G., \& Mitchell, D. (1993). Worlds of welfare and families of nations. In F. G. Castles (Ed.), Families of nations: Patterns of public policy in western democracies (pp. 92-128). Aldershot, UK: Dartmouth Publishing Co.

Coppedge, M., Gerring, J., Knutsen, C. H., Lindberg, S. I., Teorell, J., Alizada, N., ... Ziblatt, D. (2020). V-Dem [Country-Year/Country-Date] Dataset v11.1. University of Gothenburg: Varieties of Democracy (V-Dem) Project.

Cox, G. W. (1997). Making Votes Count: Strategic Coordination in the World's Electoral Systems. Cambridge, UK: Cambridge University Press.

D'Art, D., \& Turner, T. (2007). Trade Unions and Political Participation in the European Union: Still Providing a Democratic Dividend? British Journal of Industrial Relations, 45(1), 103-126.

Dassonneville, R., \& Hooghe, M. (2017). Voter turnout decline and stratification: Quasiexperimental and comparative evidence of a growing educational gap. Politics, 37(2), 184-200. 
Dekker, P., \& Van Den Broek, A. (2005). Involvement in voluntary associations in North America and Western Europe: Trends and correlates 1981-2000. Journal of Civil Society, $1(1), 45-59$.

Dingler, S. C., Kroeber, C., \& Fortin-Rittberger, J. (2019). Do parliaments underrepresent women's policy preferences? Exploring gender equality in policy congruence in 21 European democracies. Journal of European Public Policy, 26 (2), 302-321.

Ebbinghaus, B., \& Visser, J. (1999). When Institutions Matter-Union Growth and Decline in Western Europe, 1950-1995. European Sociological Review, 15(2), 135-158.

Esping-Andersen, G. (1990). The Three Worlds of Welfare Capitalism. Cambridge, UK: Polity.

Fellowes, M. C., \& Rowe, G. (2004). Politics and the New American Welfare States. American Journal of Political Science, 48(2), 362-373.

Ferrera, M. (1996). The 'Southern Model' of Welfare in Social Europe. Journal of European Social Policy, 6(1), 17-37.

Filetti, A., \& Janmaat, J. G. (2018). Income inequality and economic downturn in Europe: a multilevel analysis of their consequences for political participation. Acta Politica, 53(3), $327-347$.

Fraga, B. L. (2018). The Turnout Gap: Race, Ethnicity, and Political Inequality in a Diversifying America. New York: Cambridge University Press.

Franklin, M. N. (2004). Voter Turnout and the Dynamics of Electoral Competition in Established Democracies Since 1945. Cambridge, UK: Cambridge University Press.

Galbraith, J. K., \& Hale, J. T. (2008). State Income Inequality and Presidential Election Turnout and Outcomes. Social Science Quarterly, 89(4), 887-901.

Gallego, A. (2008). Unequal Political Participation in Europe. International Journal of Sociology, 37(4), 10-25.

Gallego, A. (2010). Understanding unequal turnout: Education and voting in comparative perspective. Electoral Studies, 29(2), 239-248.

Gallego, A. (2015). Unequal Political Participation Worldwide. New York: Cambridge University Press.

Gerber, A. S., Gruber, J., \& Hungerman, D. M. (2016). Does Church Attendance Cause People to Vote? Using Blue Laws' Repeal to Estimate the Effect of Religiosity on Voter Turnout. British Journal of Political Science, 46(3), 481-500.

Giger, N., Rosset, J., \& Bernauer, J. (2012). The Poor Political Representation of the Poor in a Comparative Perspective. Representation, 48(1), 47-61.

Gilens, M. (2005). Inequality and Democratic Responsiveness. Public Opinion Quarterly, $69(5), 778-796$. 
Goodin, R., \& Dryzek, J. (1980). Rational Participation: The Politics of Relative Power. British Journal of Political Science, 10(3), 273-292.

Hajnal, Z. L. (2010). America's Uneven Democracy: Race, Turnout, and Representation in City Politics. New York: Cambridge University Press.

Hakhverdian, A., van der Brug, W., \& de Vries, C. (2011). The Emergence of a 'Diploma Democracy'? The Political Education Gap in the Netherlands, 1971-2010. Acta Politica, $47(3), 229-247$.

Karp, J. A., \& Banducci, S. A. (2004). Political Parties and Party Mobilisation. In J. Vowles, P. Aimer, S. A. Banducci, J. A. Karp, \& R. Miller (Eds.), Voters'veto: The 2002 election in new zealand and the consolidation of minority government (pp. 104-116). Auckland: Auckland University Press.

Karp, J. A., \& Banducci, S. A. (2008). Political Efficacy and Participation in Twenty-Seven Democracies: How Electoral Systems Shape Political Behaviour. British Journal of Political Science, 38(2), 311-334.

Kasara, K., \& Suryanarayan, P. (2015). When Do the Rich Vote Less Than the Poor and Why? Explaining Turnout Inequality across the World. American Journal of Political Science, 59(3), 613-627.

Leibfried, S. (1993). Towards a European Welfare State? On Integrating Poverty Regimes into the European Community. In C. Jones (Ed.), New Perspectives on the Welfare State in Europe (pp. 120-143). London: Routledge.

Lijphart, A. (1997). Unequal Participation: Democracy's Unresolved Dilemma. The American Political Science Review, 91(1), 1-14.

Mahoney, J., Kimball, E., \& Koivu, K. L. (2009). The Logic of Historical Explanation in the Social Sciences. Comparative Political Studies, 42(1), 114-146.

Mair, P., \& van Biezen, I. (2001). Party Membership in Twenty European Democracies, 1980-2000. Party Politics, 7(1), 5-21.

Matsubayashi, T., \& Sakaiya, S. (2020). Income inequality and income bias in voter turnout. European Journal of Political Economy, 66, 101966. doi: 10.1016/j.ejpoleco.2020.101966

Mendel, J. M., \& Korjani, M. M. (2018). A New Method for Calibrating the Fuzzy Sets Used in fsQCA. Information Sciences, 468, 155-171.

Mettler, S., \& Welch, E. (2004). Civic Generation: Policy Feedback Effects of the GI Bill on Political Involvement over the Life Course. British Journal of Political Science, 34 (3), $497-518$.

Muñoz, M. M., \& Meguid, B. M. (2021). Does party polarization mobilize or de-mobilize voters? The answer depends on where voters stand. Electoral Studies, 70, 102279. doi: 10.1016/j.electstud.2021.102279 
Oana, I.-E., \& Schneider, C. Q. (2021). A Robustness Test Protocol for Applied QCA: Theory and R Software Application. Sociological Methods \& Research. doi: 10.1177/ 00491241211036158

Oana, I.-E., Schneider, C. Q., \& Thomann, E. (2021). Qualitative Comparative Analysis Using R: A Beginner's Guide. Cambridge, MA: Cambridge University Press.

OECD, \& AIAS. (2021). Institutional Characteristics of Trade Unions, Wage Setting, State Intervention and Social Pacts. Paris: OECD Publishing. Retrieved from http:// ww. oecd.org/employment/ictwss-database.htm

Pattie, C. J., \& Johnston, R. J. (2003). Hanging on the Telephone? Doorstep and Telephone Canvassing at the British General Election of 1997. British Journal of Political Science, $33(2), 303-322$.

Pierson, P. (1993). When Effect Becomes Cause: Policy Feedback and Political Change. World Politics, 45(4), 595-628.

Prior, M. (2019). Hooked: How Politics Captures People's Interest. New York: Cambridge University Press.

Quaranta, M. (2018). Repertoires of political participation: Macroeconomic conditions, socioeconomic resources, and participation gaps in Europe. International Journal of Comparative Sociology, 59(4), 319-342.

Ragin, C. C. (2008). Redesigning Social Inquiry: Fuzzy Sets and Beyond. Chicago, IL: University of Chicago Press.

Rosset, J. (2013). Are the Policy Preferences of Relatively Poor Citizens Under-represented in the Swiss Parliament? The Journal of Legislative Studies, 19(4), 490-504.

Rubenson, D., Blais, A., Fournier, P., Gidengil, E., \& Nevitte, N. (2004). Accounting for the Age Gap in Turnout. Acta Politica, 39(4), 407-421.

Schmitt, H., Önnudóttir, E. H., Teperoglou, E., \& Vegetti, F. (2013). The True European Voter: Micro Data Codebook. Mannheim University: Mannheimer Zentrum für Europäische Sozialforschung.

Schneider, C. Q. (2018). Realists and Idealists in QCA. Political Analysis, 26 (2), 246-254.

Schneider, C. Q., \& Rohlfing, I. (2013). Combining QCA and Process Tracing in Set-Theoretic Multi-Method Research. Sociological Methods \& Research, 42(4), 559-597.

Schneider, C. Q., \& Wagemann, C. (2012). Set-Theoretic Methods for the Social Sciences: A Guide to Qualitative Comparative Analysis. Cambridge: Cambridge University Press.

Scruggs, L. A. (2007). Welfare State Generosity Across Space and Time. In J. Clasen \& N. A. Siegel (Eds.), Investigating Welfare State Change: The 'Dependent Variable Problem' in Comparative Analysis (pp. 133-166). Cheltenham, UK: Edward Elgar.

Scruggs, L. A., Jahn, D., \& Kuitto, K. (2018). Comparative Welfare Entitlements Data Set 2, 
Version 2018-12. University of Connecticut / University of Greifswald. Retrieved from http: //cwed2.org/

Siaroff, A. (1994). Work, Welfare, and Gender Equality: A New Typology. In D. Sainsbury (Ed.), Gendering Welfare States (pp. 82-100). London: Sage Publications.

Solt, F. (2008). Economic Inequality and Democratic Political Engagement. American Journal of Political Science, 52(1), 48-60.

Solt, F. (2010). Does Economic Inequality Depress Electoral Participation? Testing the Schattschneider Hypothesis. Political Behavior, 32 (2), 285-301.

Soss, J. (1999). Lessons of Welfare: Policy Design, Political Learning, and Political Action. The American Political Science Review, 93(2), 363-380.

Teixeira, R. A. (1987). Why Americans Don't Vote: Turnout Decline in the United States, 1960-1984. Westport, CT: Greenwood Press.

Topf, R. (1995). Electoral Participation. In H.-D. Klingemann \& D. Fuchs (Eds.), Citizens and the state (pp. 27-51). Oxford: Oxford University Press.

Torpe, L. (2003). Social Capital in Denmark: A Deviant Case? Scandinavian Political Studies, 26(1), 27-48.

Valentino, N. A., Brader, T., Groenendyk, E. W., Gregorowicz, K., \& Hutchings, V. L. (2011). Election Night's Alright for Fighting: The Role of Emotions in Political Participation. The Journal of Politics, 73(1), 156-170.

Verba, S., \& Nie, N. H. (1972). Participation in America: Political Democracy and Social Equality. New York: Harper \& Row.

Verba, S., Schlozman, K. L., \& Brady, H. E. (1995). Voice and Equality: Civic Voluntarism in American Politics. Cambridge, MA: Harvard University Press.

Vowles, J. (2004). Civic Engagement in New Zealand: Decline or Demise? [Inaugural Professorial Address]. University of Auckland. Retrieved 2021-08-26, from http:// www.nzes.org/docs/papers/Inaugural_2004.pdf

Wattenberg, M. P. (2000). The Decline of Party Mobilization. In R. J. Dalton \& M. P. Wattenberg (Eds.), Parties Without Partisans: Political Change in Advanced Industrial Democracies (pp. 64-76). New York: Oxford University Press.

Weßels, B. (2018). Political Inequality in Voting. In W. Merkel \& S. Kneip (Eds.), Democracy and Crisis: Challenges in Turbulent Times (pp. 49-69). Cham: Springer. 


\section{Welfare States Matter for Democracy: Online Appendix}

\section{Merging and harmonization procedures for individual-level data}

The data set from which country-election coefficients were computed has itself been obtained from national election studies carried out in each of the countries in the sample. Most of the election surveys have been harmonized from country election series; this applies to Australia, Belgium, Canada, Denmark, Finland, France, Germany, Iceland, Israel, Italy, Netherlands, New Zealand, Norway, Spain, Sweden, Switzerland, United Kingdom, United States. The remaining election surveys have been sourced from a combination of surveys found in waves 1-4 of the Comparative Study of Electoral Systems and waves 1-6 of the World Values Survey and the European Values Survey. The coding scheme used to merge the series is based entirely on the coding scheme developed by the True European Voter (TEV) project (https://www.mzes.uni-mannheim.de/d7/en/projects/the-true-european-votera-strategy-for-analysing-the-prospects-of-european-electoral-democracy-that-includes-the-west). The final goal is to allow interested researchers to merge these two data sources, albeit for a limited set of variables. ${ }^{1}$

In each instance, a few guidelines were used to determine whether an election study could be included in the sample. The data had to contain a turnout question which refers to a national-level election (either presidential or parliamentary), rather than to a regional one (for regional legislatures or executives). The second criterion refers to the type of sample collected: preference was awarded to cross-sectional samples, rather than to multi-year panels. This is the reason why the 1963-1970 Political Change in Britain survey was reduced to only the 1966 wave. The final criterion refers to timing: post-election surveys were favored. In cases where the election study consisted of a pre-election and post-election component, or was a pre/post panel, only the post-election sample was kept in the data. This was most commonly the case in the Israeli series. If no post-election survey existed, then a pre-election survey

\footnotetext{
${ }^{1}$ The TEV data has a European focus; it also strives to include voting studies conducted in Central and Eastern Europe. On the other hand, the data used here expands the TEV's OECD coverage, by including countries outside of continental Europe and the UK, such as Australia, New Zealand, or the US.
} 
Table 1: Sample coverage for individual-level data

\begin{tabular}{ll}
\hline Country & Period \\
\hline Australia & $1977-2019$ \\
Austria & $1999-2017$ \\
Belgium & $1991-1999$ \\
Canada & $1965-2015$ \\
Denmark & $1971-2011$ \\
Finland & $1972-2015$ \\
France & $1962-2017$ \\
Germany & $1953-2017$ \\
Greece & $2009-2015$ \\
Iceland & $1987-2017$ \\
Ireland & $2002-2016$ \\
Israel & $1969-2013$ \\
Italy & $1972-2018$ \\
Japan & $1990-2010$ \\
Netherlands & $1971-2012$ \\
New Zealand & $1981-2017$ \\
Norway & $1957-2017$ \\
Portugal & $2002-2015$ \\
Spain & $2000-2019$ \\
Sweden & $1960-2006$ \\
Switzerland & $1975-2015$ \\
United Kingdom & $1966-2017$ \\
United States & $1952-2016$ \\
\hline
\end{tabular}

Note: This comprises the sample of 226 surveys hich are plotted in Figure 1 in the main manuscript. In many cases not all elections within a specific period could be included in the sample, owing to data availability issues.

was used - in these instances the turnout question was phrased as an intention. Within these constraints the studies presented in Table 1 were accepted for inclusion in the final sample.

When merging the surveys the goal has been to maximize coverage of elections and countries, while maintaining cross-national comparability of the concepts being measured. Deciding whether to consider two items from different surveys as equivalent involved striking a balance between the coverage-comparability trade off mentioned above. Since the national election studies brought together here were not initially implemented with the goal of cross-national comparability in mind, the procedures followed (see following section) have resulted in an admittedly patchy data set in terms of missing information.

The following sources have been used for the individual-level data used as part of the process 
of producing the turnout gap coefficients:

- Australia: the Australian National Political Attitudes Study, the Australian National Elections Study;

- Austria: World Values Surveys, waves 3-5 of the CSES;

- Belgium: the Belgian National Elections Study;

- Canada: the Canadian National Elections Study;

- Denmark: the 1971-2005 merged file for the Danish Elections Study, the 2007 and 2011 waves of the Danish Elections Study;

- Finland: select years from the Finnish Voter Barometer, the Finnish National Election Study;

- France: the French National Elections Study;

- Germany: the German Federal Elections Series hosted by GESIS (Leibniz Institute for the Social Sciences);

- Greece: waves 3 and 4 of the CSES;

- Iceland: the Icelandic National Election Study;

- Ireland: waves $2-4$ of the CSES;

- Israel: the Israeli National Elections Study;

- Italy: the Italian National Elections Study;

- Japan: World Values Surveys, waves 1-4 of the CSES;

- Netherlands: the Dutch Parliamentary Election Study;

- New Zealand: the New Zealand Election Study, electoral surveys conducted in 1981 and 1987 ;

- Norway: the Norwegian Election Study;

- Portugal: the 2012 Elections, Leadership, and Responsibility study, waves 2-4 of the CSES;

- Spain: Spanish National Election Study; 
- Sweden: the Swedish National Election Study;

- Switzerland: the cumulated file 1971-2015 of the Swiss National Election Studies;

- United Kingdom: the 1963-1970 Political Change in Britain study, the British Election Study series;

- United States: 1948-2012 American National Elections Study time series cumulative data file; 2016 ANES Time Series Study.

The guidelines on the basis of which the merging of the data was done have been developed by the TEV project team (Schmitt, Önnudóttir, Teperoglou, \& Vegetti, 2013). They have been followed here as closely as possible, with a view toward ultimately merging the two data sources. The following structure has been maintained, as found in the TEV:

- Age: number of years;

- Gender: $1=$ female, $2=$ male;

- Education: 1=primary (complete or incomplete, and incomplete secondary), $2=$ secondary completed, $3=$ (at least some) higher education;

- Income: $1=$ lowest tertile, $2=$ middle tertile; $3=$ highest tertile.

Gender and age were the least problematic indicators in the merging process. As would be expected, the scale for gender did not vary between survey series. For age, most surveys recorded age in years; a few chose to record the year of birth, which could easily be transformed into years. In the case of Denmark (1981, 1988 and 1990), Israel (1969 and 1973), Finland (1975, 1983 and 1987), and France (1962 and 2012), age was recorded using distinct categories (usually brackets of 10-15 years). In these instances, no procedure could adequately recover the information lost through using categories. Given that they affect a very small share of the respondents in the data, the solution adopted here was to recode the categories into the average age of the bracket (e.g. 25-29 was replaced by 27$).^{2}$

Education posed a more complex set of problems when it came to processing the different educational levels that exist in the 23 countries into a tripartite division: primary education (including incomplete secondary studies), completed secondary education, and college (including an incomplete BA degree, and any post-graduate studies). The first difficulty was caused by the issue of vocational education, which doesn't easily fit into this structure.

\footnotetext{
${ }^{2}$ While undeniably problematic, this strategy was considered preferable to losing 10 surveys from the sample.
} 
As a general rule, if vocational studies were pursued after lower secondary education (8th or 9th grade), they were considered part of the "secondary incomplete" sub-category. If these studies were taken up after the completion of the secondary cycle, however, as in the German apprenticeship system, they were considered part of the "completed secondary studies" category. ${ }^{3}$ The second difficulty, exhibited by the Australian series, is that the specific items measuring educational achievement do not ask for highest educational level reached, but rather the number of years spent in primary, secondary and tertiary education. On the basis of these a rough categorization could be made.

A bigger complication is found in the case of Denmark, where it proved impossible to clearly distinguish between those who stopped at a high school degree, and those who chose to continue with a college degree or an apprenticeship. The merged data file for Denmark (1971-2005) places in the same category those with a high school degree and those who went on to college or further. With no remedial measures available, I recoded the " $12+$ years of education" category to designate "some college education". ${ }^{4}$ The case of the United Kingdom illustrates a third problem - the item on education measures the age at which full-time education has been terminated. With no other course of action available, education was recoded using the 16 and 18 year thresholds. As a rule, 16 or below denotes primary or incomplete secondary education, 17-18 suggests secondary education has been completed, while 19 and above denotes the respondent has at least some college. The 16 years threshold has been chosen under the assumption that those who drop out are more likely to do so at the beginning of the upper secondary cycle (15-16 years) rather than at the end of it, just in sight of high school graduation. Even so, this procedure will surely misclassify individuals who have interrupted their full-time studies and have continued them at a later date.

Income is another indicator which has proven difficult to harmonize across all the studies included here. The TEV project measures income using tertiles, a practice which is followed here as well. However, even a scale as rough as this posed challenges for the variety of ways in which the income of the household is measured across studies. Where income has been

\footnotetext{
${ }^{3}$ The exception here is Finland, where vocational education can extend all throughout college, and results in this case in an applied sciences degree. In these instances, vocational studies pursued at the college level were considered part of the tertiary cycle.

${ }^{4}$ Even when using the individual Danish studies, information about college education doesn't exist prior to 1984. It should be also mentioned that the bias introduced by such coding procedure will be smaller in the case of more recent surveys. As labor market opportunities for high school graduates have diminished, and tertiary education has expanded, a lower share of people in the "12+ years of education" category is expected to have only stopped at a high school degree. A 2005 OECD "Education at a Glance" report (OECD, 2005, Graph 1.1a) suggests that about $32 \%$ of people in the 25-64 age category had a college degree in Denmark in 2002. This is not far from the estimate of $30.5 \%$ in the 2001 survey, which includes those with some college as well as everyone above 18 years of age.
} 
measured in raw currency, this has been a simple procedure (e.g. Norway in 2009, or Canada in 2015). In most other countries, though, income was measured with a ordinal scale, ranging from 7 categories in the Danish 1971 study to 22 in the Australian 2013 one. Additionally, all studies obtained from the CSES measure income in quintiles. With the scale available in the surveys we then proceeded to construct the tertiles as closely as possible to the $33.3 \%$ standard. The outcome has varied. For the 2011 Canadian survey, the tertiles produced have 716, 718 and 710 members, respectively. On the other hand, the best division for Spain in 2011 produced groups of size 1,222, 1,957 and 1,205. Other instances of skewed allocation are France in 1988 (1,573, 1,501 and 541), or New Zealand in 1981 (338, 625 and 481). Thankfully, most countries are in between these two sets of extremes, with deviations of 3-5 percentage points from the standard $33.3 \%$ cutoff.

In addition to the imprecision caused by the uneven group size, other factors also affect the quality of the income measure. Chief among them is the occasional need to include personal income estimates into a series that predominantly refers to household income. A total of 12 election studies use the respondent's income as a measure: Denmark (1971), Finland (1995, 1999 and 2011), New Zealand (1981), Norway (1957), Sweden (1968, 1970, 1994, 1998, and 2006) and the United Kingdom (1966). For a further 4 studies no information about whether the measure refers to personal or household income could be found (Sweden in 1982, 1985, 1988, and 2002). With a continuous income scale and information about the number of adults and children in the household, a rough equivalence could have been established. In their absence, though, no corrective measure could be taken, and the measurements were included in the data as found.

When compared to education and income, the difficulties encountered in joining together the turnout items appear minor in relative terms. With the exception of the United Kingdom 1966 study, all other questions use a simple "yes/no" dichotomous scale for the answer. In the UK case, the item allowed for a "fairly sure voted" option, which was folded into the "definitely voted" category. Refusals to answer or claims of not remembering whether the person voted were coded as "missing". Casting a blank vote was recoded as having turned out in the two studies which included such a response option. Where turnout and vote choice information were part of the same item, a simple recoding procedure compressed this into a dichotomous scale. The more important aspect with regard to turnout is the format of the question - whether it reports a part behavior or a vote intention. The preference has been for past behavior, and the majority of the surveys included in the data report this: only Israel (1973 and 1977) and Japan (2000 and 2010) have items that refer to vote intention. 


\section{Macro variables: coding and sources}

The QCA analysis uses as predictors (conditions) a set of commonly-encountered aggregate characteristics related to the welfare state and the labor market. The first such indicator is a combined index of union strength, obtained by combining with logical OR $(+)$ the sets high union density and high union centralization. Union density is expressed as the percentage of unionized workers out of the entire labor force. The data is obtained from the OECD/AIAS database on Institutional Characteristics of Trade Unions, Wage Setting, State Intervention and Social Pacts (ICTWSS), February 2021 version (https://www. oecd.org/employment/ ictwss-database.htm); the original variable name is UD_hist. A few gaps in the data had to be filled by hand in the interest of maximizing coverage. In the case of Israel most observations were missing, and had to be replaced with records available in version 6.1 of the ICTWSS (from October 2019). In instances where a gap in the series existed, linear interpolation was performed, assuming a constant year-to-year change in union density; this was the case, for example, in Canada (1993), France (1995, 2007, 2012, and 2017), Iceland (1987), United States (1982) and others. In total, 28 such values were manually inputted. Higher values here denote a more unionized workforce. Union centralization is taken from David Brady, Evelyne Huber, and John D. Stephens' Comparative Welfare States Dataset (CWD), January 2020 version. This indicator was measured on a 9-point scale, from 0 (decentralized, fragmented unions) to 8 (centralized, with unions organized in a few national-level confederations).

The second indicator is a combined index of welfare generosity, taken from Lyle Scruggs, Detlef Jahn, and Kati Kuitto's Comparative Welfare Entitlements Dataset, December 2018 version (http://cwed2.org/download.php). The index aggregates generosity from three areas: unemployment, pension, and sickness benefits. The index values take into account both replacement rates, as well as how strict the eligibility rules are, the coverage of the schemes, and the length of coverage. Higher values on this index refer to a more generous welfare state. Information for all countries covers the 1971-2002 period.

The third included condition is an indicator of educational equality, sourced from the V-DEM data (https://www.v-dem.net/en/), version 11.1 (original variable name is v2peedueq). This item assesses the extent to which high-quality basic education is available to all citizens in the country, and is measured on a 5-point scale, ranging from 0 (extremely unequal provision, with at least three quarters of children receiving low-quality education) to 4 (provision of quality education is essentially equal, with fewer than 5 percent of children receiving low-quality education). The final included condition is an indicator of the type of welfare policy that is predominant in the country, also sourced from V-DEM (original variable name is v2dlunivl). 
The item measures whether to what extent welfare programs in the country are universal, as opposed to means-tested; higher values denote a higher share of universalistic programs in the welfare state. 


\section{Truth table for outcome}

Table 2 on page 10 presents the truth table for the outcome we use in our QCA analysis: low turnout gaps. 


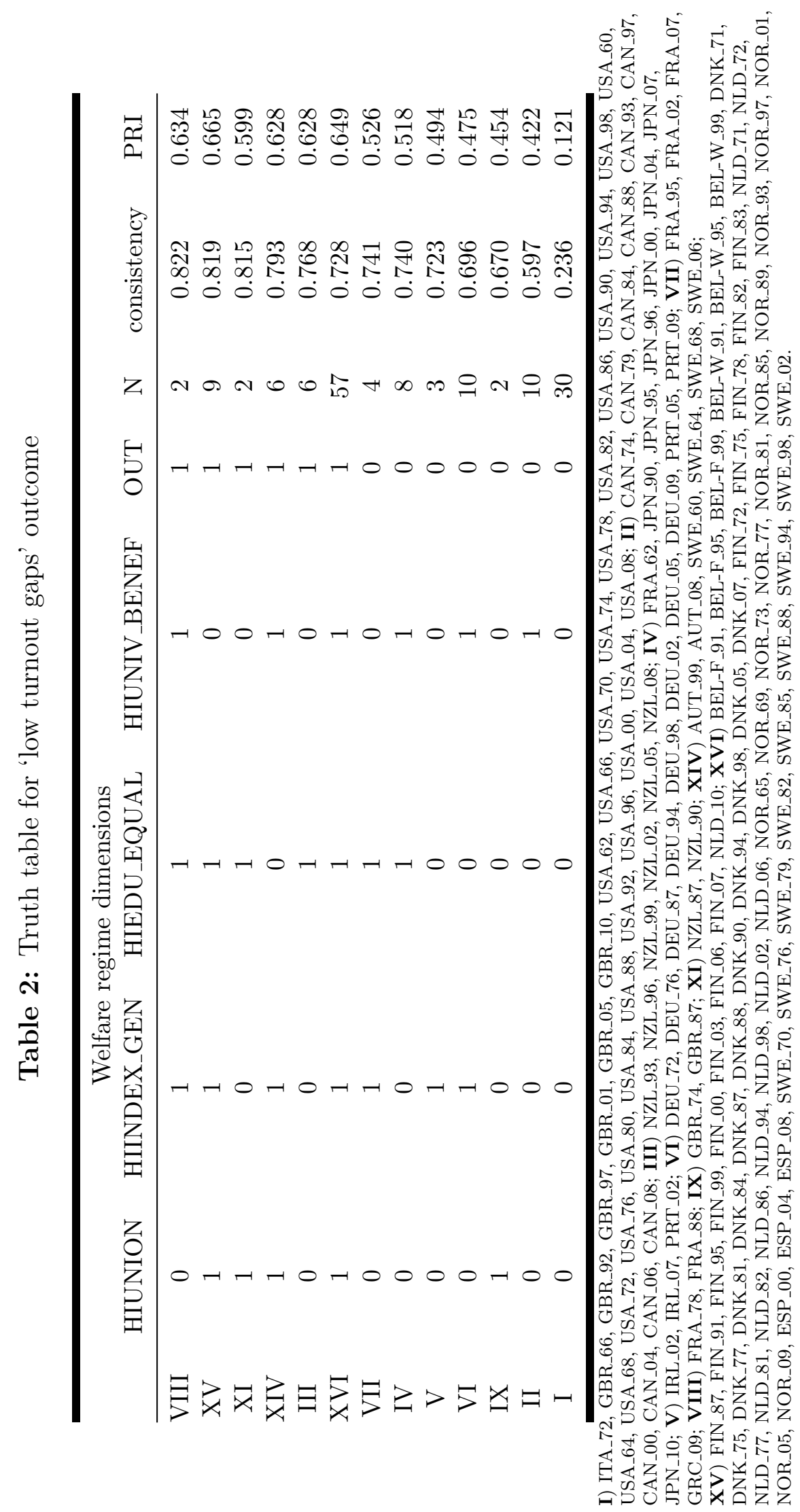




\section{Results from analysis of necessity}

In the tables below we present a few tables of results from the analysis of necessity we conducted prior to the analysis of sufficiency of the "low turnout gaps" outcome. In Table 3 we present the parameters of fit from this analysis of necessity.

Table 3: Parameters of fit: conditions for low turnout gaps

\begin{tabular}{lrrr}
\hline Conditions & Consistency score & Coverage score & Relevance of Necessity \\
\hline HIINDEX_GEN & 0.730 & 0.644 & 0.663 \\
HIEDU_EQUAL & 0.798 & 0.687 & 0.678 \\
HIUNIV_BENEF & 0.747 & 0.693 & 0.719 \\
HIUNION & 0.698 & 0.660 & 0.707 \\
$\sim$ HIINDEX_GEN & 0.329 & 0.416 & 0.710 \\
$\sim$ HIEDU_EQUAL & 0.305 & 0.399 & 0.716 \\
$\sim$ HIUNIV_BENEF & 0.399 & 0.471 & 0.706 \\
$\sim$ HIUNION & 0.355 & 0.408 & 0.673 \\
\hline
\end{tabular}

In Table 4 we present the superset relations revealed by our necessity analysis of low turnout gaps.

Table 4: Superset relations for analysis of low turnout gaps

\begin{tabular}{lccc}
\hline Term & & & \\
& Inclusion & Relevance & Coverage \\
\hline HIINDEX_GEN + HIEDU_EQUAL & 0.904 & 0.534 & 0.655 \\
HIEDU_EQUAL + HIUNIV_BENEF & 0.909 & 0.549 & 0.665 \\
\hline
\end{tabular}

In Figure 1 we present an $\mathrm{XY}$ plot for the HIINDEX_GEN + HIEDU_EQUAL necessary term uncovered by our analysis. 
Figure 1: XY plot for HIINDEX_GEN + HIEDU_EQUAL necessary term

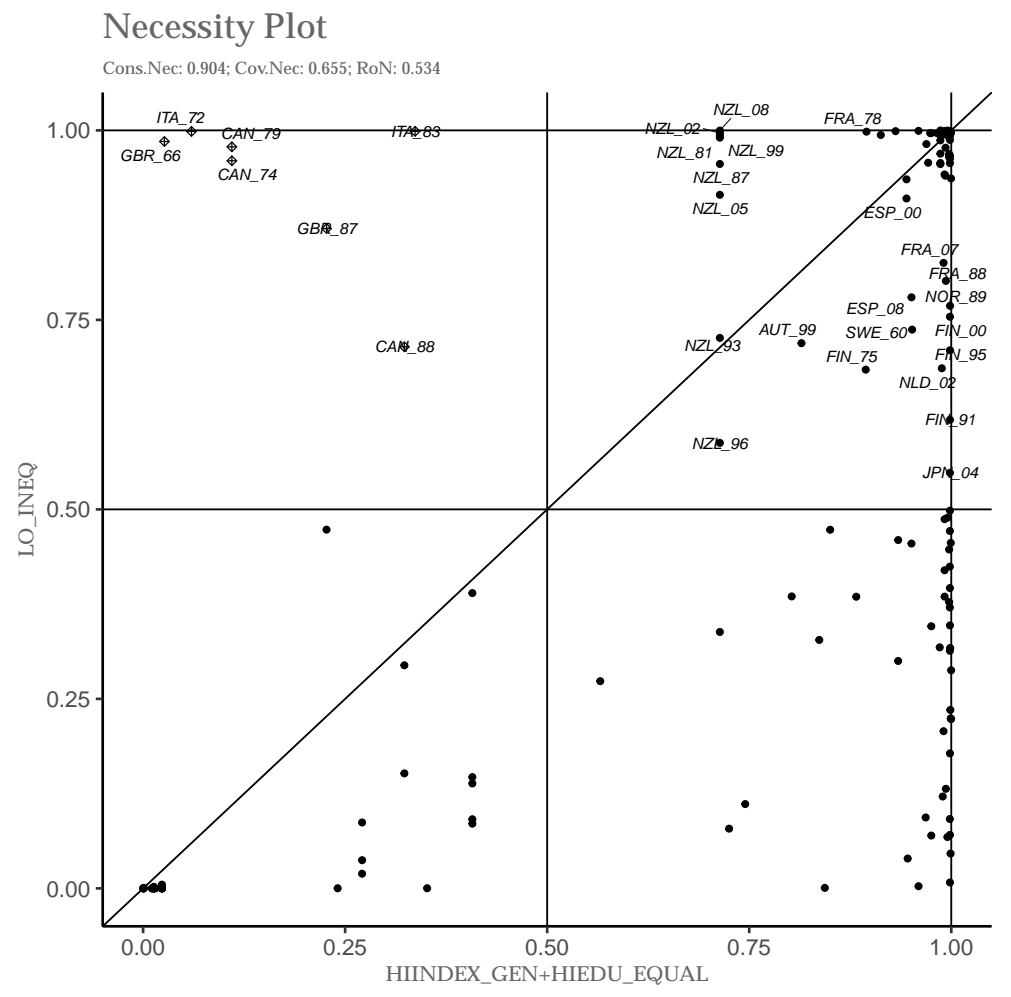




\section{Sample size for mechanism tests}

One important characteristic of our investigation of mechanisms of transmission is that the sample composition in terms of country years changes from one survey wave to another depending on the availability of cases. Our mobilizing, supportive, and globally uncovered clusters contain a host of country years; some of these are available in some survey programs but not in others. As a result, the precise composition of the three clusters is variable. Additionally, some country years might drop out of a specific comparison if a specific item, say, on political efficacy, was not asked in a specific country in a survey round. To give a complete picture to the reader we have decided to provide here two tables which contain the sample sizes (both in terms of country years and respondents) for each of the tests we conduct.

Table 5: Sample sizes for mechanism analyses: mobilizing versus uncovered results

\begin{tabular}{|c|c|c|c|c|c|c|c|}
\hline Survey & Wave & Mechanism & Item & $\begin{array}{l}\text { No. countries } \\
\text { mobilizing }\end{array}$ & $\begin{array}{l}\text { No. countries } \\
\text { comparison }\end{array}$ & $\begin{array}{l}\text { No. respondents } \\
\text { mobilizing }\end{array}$ & $\begin{array}{c}\text { No. respondents } \\
\text { comparison }\end{array}$ \\
\hline ISSP RoG & 4 & Bureaucratic & 1 & 4 & 6 & 4727 & 6080 \\
\hline ISSP RoG & 4 & responsiveness & 2 & 4 & 6 & 4827 & 6141 \\
\hline CSES & 1 & & 1 & 5 & 6 & 7036 & 8937 \\
\hline CSES & 1 & & 2 & 4 & 6 & 2472 & 5828 \\
\hline CSES & 2 & & 1 & 4 & 7 & 4902 & 8864 \\
\hline CSES & 2 & & 1 & 4 & 7 & 2812 & 6316 \\
\hline CSES & 3 & & 1 & 5 & 7 & 7172 & 10713 \\
\hline CSES & 3 & & 2 & 5 & 7 & 3323 & 8287 \\
\hline ESS & 1 & & 1 & 5 & 3 & 7637 & 5124 \\
\hline ESS & 1 & Party & 2 & 5 & 3 & 4409 & 2529 \\
\hline ESS & 2 & closeness & 1 & 5 & 5 & 7029 & 7899 \\
\hline ESS & 2 & & 2 & 5 & 5 & 4158 & 3848 \\
\hline ESS & 3 & & 1 & 4 & 4 & 5834 & 6899 \\
\hline ESS & 3 & & 2 & 4 & 4 & 3676 & 3294 \\
\hline ESS & 4 & & 1 & 4 & 4 & 6227 & 6468 \\
\hline ESS & 4 & & 2 & 4 & 4 & 3706 & 3188 \\
\hline ESS & 5 & & 1 & 3 & 3 & 4183 & 6104 \\
\hline ESS & 5 & & 2 & 3 & 3 & 2850 & 2616 \\
\hline CSES & 1 & & 1 & 6 & 6 & 8243 & 8995 \\
\hline CSES & 1 & & 2 & 6 & 6 & 8219 & 9014 \\
\hline CSES & 2 & & 1 & 4 & 7 & 5010 & 8815 \\
\hline CSES & 2 & & 2 & 3 & 7 & 3624 & 8822 \\
\hline CSES & 3 & & 1 & 5 & 7 & 7197 & 10719 \\
\hline
\end{tabular}


Table 5: Sample sizes for mechanism analyses: mobilizing versus uncovered results (continued)

\begin{tabular}{|c|c|c|c|c|c|c|c|}
\hline Survey & Wave & Mechanism & Item & $\begin{array}{c}\text { No. countries } \\
\text { mobilizing }\end{array}$ & $\begin{array}{c}\text { No. countries } \\
\text { comparison }\end{array}$ & $\begin{array}{l}\text { No. respondents } \\
\text { mobilizing }\end{array}$ & $\begin{array}{c}\text { No. respondents } \\
\text { comparison }\end{array}$ \\
\hline CSES & 3 & \multirow{17}{*}{$\begin{array}{l}\text { Political } \\
\text { efficacy }\end{array}$} & 2 & 5 & 6 & 7213 & 8859 \\
\hline ESS & 1 & & 1 & 5 & 3 & 7677 & 5137 \\
\hline ESS & 1 & & 2 & 5 & 3 & 7704 & 5148 \\
\hline ESS & 1 & & 3 & 5 & 3 & 7654 & 5139 \\
\hline ESS & 1 & & 4 & 5 & 3 & 7632 & 5120 \\
\hline ESS & 1 & & 5 & 5 & 3 & 7650 & 5129 \\
\hline ESS & 2 & & 1 & 5 & 5 & 7093 & 7934 \\
\hline ESS & 2 & & 2 & 5 & 5 & 7086 & 7895 \\
\hline ESS & 3 & & 1 & 4 & 4 & 5851 & 6937 \\
\hline ESS & 3 & & 2 & 4 & 4 & 5840 & 6911 \\
\hline ESS & 4 & & 1 & 4 & 4 & 6270 & 6489 \\
\hline ESS & 4 & & 2 & 4 & 4 & 6272 & 6481 \\
\hline ISSP RoG & 4 & & 1 & 4 & 6 & 4976 & 6415 \\
\hline ISSP RoG & 4 & & 2 & 4 & 6 & 4889 & 6360 \\
\hline ISSP RoG & 4 & & 3 & 4 & 6 & 4933 & 6312 \\
\hline ISSP RoG & 4 & & 4 & 4 & 6 & 4891 & 6315 \\
\hline ISSP RoG & 4 & & 5 & 4 & 6 & 4897 & 6329 \\
\hline CSES & 1 & \multirow{8}{*}{$\begin{array}{l}\text { Political } \\
\text { information }\end{array}$} & 1 & 6 & 6 & 8790 & 9174 \\
\hline CSES & 2 & & 1 & 4 & 7 & 5066 & 8994 \\
\hline CSES & 3 & & 1 & 5 & 7 & 7691 & 12971 \\
\hline ESS & 1 & & 1 & 5 & 3 & 7734 & 5160 \\
\hline ESS & 2 & & 1 & 5 & 5 & 7113 & 7942 \\
\hline ESS & 3 & & 1 & 4 & 4 & 5886 & 6960 \\
\hline ESS & 4 & & 1 & 4 & 4 & 6290 & 6475 \\
\hline ESS & 5 & & 1 & 3 & 3 & 4230 & 6129 \\
\hline CSES & 2 & Mobilization & 1 & 4 & 7 & 5050 & 8894 \\
\hline CSES & 2 & \multirow{5}{*}{ Participation } & 1 & 4 & 7 & 5066 & 8994 \\
\hline ESS & 2 & & 1 & 5 & 5 & 7134 & 7980 \\
\hline ESS & 3 & & 1 & 4 & 4 & 5904 & 6983 \\
\hline ESS & 4 & & 1 & 4 & 4 & 6313 & 6516 \\
\hline ESS & 5 & & 1 & 3 & 3 & 4238 & 6167 \\
\hline CSES & 1 & \multirow{7}{*}{$\begin{array}{l}\text { Union } \\
\text { membership }\end{array}$} & 1 & 5 & 6 & 6772 & 8672 \\
\hline CSES & 2 & & 1 & 4 & 7 & 5045 & 8078 \\
\hline CSES & 3 & & 1 & 4 & 7 & 6457 & 12924 \\
\hline ESS & 1 & & 1 & 5 & 3 & 7732 & 5164 \\
\hline ESS & 2 & & 1 & 5 & 5 & 7125 & 7971 \\
\hline ESS & 3 & & 1 & 4 & 4 & 5898 & 6973 \\
\hline ESS & 4 & & 1 & 4 & 4 & 6302 & 6513 \\
\hline
\end{tabular}


Table 5: Sample sizes for mechanism analyses: mobilizing versus uncovered results (continued)

\begin{tabular}{lccccccc}
\hline Survey & Wave & Mechanism & Item & $\begin{array}{c}\text { No. countries } \\
\text { mobilizing }\end{array}$ & $\begin{array}{c}\text { No. countries } \\
\text { comparison }\end{array}$ & $\begin{array}{c}\text { No. respondents } \\
\text { mobilizing }\end{array}$ & $\begin{array}{c}\text { No. respondents } \\
\text { comparison }\end{array}$ \\
\hline ESS & 5 & 1 & 3 & 3 & 4231 & 6151 \\
ISSP RoG & 4 & 1 & 4 & 6 & 5090 & 5922 \\
\hline
\end{tabular}

Table 6: Sample sizes for mechanism analyses: supportive versus uncovered

\begin{tabular}{|c|c|c|c|c|c|c|c|}
\hline Survey & Wave & Mechanism & Item & $\begin{array}{l}\text { No. countries } \\
\text { supportive }\end{array}$ & $\begin{array}{c}\text { No. countries } \\
\text { comparison }\end{array}$ & $\begin{array}{c}\text { No. respondents } \\
\text { supportive }\end{array}$ & $\begin{array}{c}\text { No. respondents } \\
\text { comparison }\end{array}$ \\
\hline ISSP RoG & 4 & Bureaucratic & 1 & 3 & 6 & 3829 & 6080 \\
\hline ISSP RoG & 4 & responsiveness & 2 & 3 & 6 & 3841 & 6141 \\
\hline CSES & 1 & & 1 & 6 & 6 & 8565 & 9143 \\
\hline CSES & 2 & & 1 & 3 & 7 & 4001 & 8940 \\
\hline CSES & 3 & & 1 & 3 & 7 & 3827 & 12921 \\
\hline ESS & 1 & & 1 & 4 & 3 & 5796 & 5161 \\
\hline ESS & 1 & & 2 & 4 & 3 & 5872 & 5167 \\
\hline ESS & 2 & Education & 1 & 4 & 5 & 5299 & 7934 \\
\hline ESS & 2 & & 2 & 4 & 5 & 5320 & 7879 \\
\hline ESS & 3 & & 1 & 3 & 4 & 4076 & 6940 \\
\hline ESS & 3 & & 2 & 3 & 4 & 4119 & 6969 \\
\hline ISSP RoG & 4 & & 1 & 3 & 6 & 3544 & 6221 \\
\hline ISSP RoG & 4 & & 2 & 3 & 6 & 4001 & 6548 \\
\hline CSES & 1 & & 1 & 6 & 6 & 8243 & 8995 \\
\hline CSES & 1 & & 2 & 6 & 6 & 8219 & 9014 \\
\hline CSES & 2 & & 1 & 3 & 7 & 3965 & 8815 \\
\hline CSES & 2 & & 2 & 2 & 7 & 2580 & 8822 \\
\hline CSES & 3 & & 1 & 3 & 7 & 3943 & 10719 \\
\hline CSES & 3 & & 2 & 3 & 6 & 3945 & 8859 \\
\hline ESS & 1 & & 1 & 4 & 3 & 5820 & 5137 \\
\hline ESS & 1 & & 2 & 4 & 3 & 5841 & 5148 \\
\hline ESS & 1 & & 3 & 4 & 3 & 5803 & 5139 \\
\hline ESS & 1 & Political & 4 & 4 & 3 & 5782 & 5120 \\
\hline ESS & 1 & efficacy & 5 & 4 & 3 & 5808 & 5129 \\
\hline ESS & 2 & & 1 & 4 & 5 & 5291 & 7934 \\
\hline ESS & 2 & & 2 & 4 & 5 & 5288 & 7895 \\
\hline ESS & 3 & & 1 & 3 & 4 & 4075 & 6937 \\
\hline ESS & 3 & & 2 & 3 & 4 & 4065 & 6911 \\
\hline ISSP RoG & 4 & & 1 & 3 & 6 & 3987 & 6415 \\
\hline ISSP RoG & 4 & & 2 & 3 & 6 & 3910 & 6360 \\
\hline
\end{tabular}


Table 6: Sample sizes for mechanism analyses: supportive versus uncovered (continued)

\begin{tabular}{|c|c|c|c|c|c|c|c|}
\hline Survey & Wave & Mechanism & Item & $\begin{array}{c}\text { No. countries } \\
\text { supportive }\end{array}$ & $\begin{array}{c}\text { No. countries } \\
\text { comparison }\end{array}$ & $\begin{array}{c}\text { No. respondents } \\
\text { supportive }\end{array}$ & $\begin{array}{c}\text { No. respondents } \\
\text { comparison }\end{array}$ \\
\hline ISSP RoG & 4 & & 3 & 3 & 6 & 3963 & 6312 \\
\hline ISSP RoG & 4 & & 4 & 3 & 6 & 3952 & 6315 \\
\hline ISSP RoG & 4 & & 5 & 3 & 6 & 3919 & 6329 \\
\hline CSES & 1 & & 1 & 6 & 6 & 8790 & 9174 \\
\hline CSES & 2 & & 1 & 3 & 7 & 4006 & 8994 \\
\hline CSES & 3 & Political & 1 & 3 & 7 & 3993 & 12971 \\
\hline ESS & 1 & information & 1 & 4 & 3 & 5871 & 5160 \\
\hline ESS & 2 & & 1 & 4 & 5 & 5307 & 7942 \\
\hline ESS & 3 & & 1 & 3 & 4 & 4108 & 6960 \\
\hline CSES & 1 & & 1 & 6 & 6 & 8223 & 8972 \\
\hline CSES & 1 & Political & 2 & 6 & 6 & 8177 & 8963 \\
\hline CSES & 2 & representation & 1 & 3 & 7 & 3813 & 8581 \\
\hline CSES & 2 & & 2 & 3 & 7 & 3789 & 8417 \\
\hline CSES & 3 & & 1 & 2 & 7 & 1553 & 10463 \\
\hline ESS & 3 & Unempl. concern & 1 & 3 & 4 & 2494 & 3717 \\
\hline
\end{tabular}




\section{Cluster diagnostics}

Our main analysis is reported using the full sample of country years, which in some cases spans multiple decades. To ensure that our core results are not driven by the pooling of cases, we repeat out analysis across multiple time periods. We present these cluster diagnostics (Oana, Schneider, \& Thomann, 2021) for the analysis of necessity below, in Table 7 on page 17. The periods used are: 1960-1982 (1), 1986-2001 (2), and 2002-2010 (3).

Table 7: Cluster diagnostics for necessity analysis: 3 time periods

\begin{tabular}{lccc}
\hline & Consistencies & Distances & Coverages \\
\hline Between 1 (55) & 0.930 & & 0.758 \\
Between 2 (58) & 0.993 & & 0.705 \\
Between 3 (39) & 0.896 & & 0.582 \\
\hline Pooled & 0.909 & 0.025 & 0.665 \\
Between to pooled & & 0.025 \\
\hline
\end{tabular}

In Table 8, on the other hand, we present the same cluster diagnostics for the same 3 periods of time, but for the analysis of sufficiency that we report in the manuscript. 
Table 8: Cluster diagnostics for sufficiency analysis: 3 time periods

\begin{tabular}{lccc}
\hline & Consistencies & Distances & Coverages \\
\hline & \multicolumn{3}{c}{ HIUNION*HIEDU_EQUAL } \\
Between 1 (55) & 0.805 & & 0.712 \\
Between 2 (58) & 0.712 & & 0.703 \\
Between 3 (39) & 0.667 & & 0.481 \\
\hline Pooled & 0.689 & \multirow{2}{*}{0.046} & 0.610 \\
Between to pooled & & & \\
\hline
\end{tabular}

\begin{tabular}{|c|c|c|}
\hline Between 1 (55) & 0.788 & 0.802 \\
\hline Between 2 (58) & 0.737 & 0.560 \\
\hline Between 3 (39) & 0.676 & 0.456 \\
\hline $\begin{array}{l}\text { Pooled } \\
\text { Between to pooled }\end{array}$ & 0.720 & 0.606 \\
\hline
\end{tabular}

\begin{tabular}{|c|c|c|}
\hline & \multicolumn{2}{|c|}{ HIINDEX_GEN*HIEDU_EQUAL* HIUNIV_BENEF } \\
\hline Between 1 (55) & 0.929 & 0.063 \\
\hline Between 2 (58) & 0.958 & 0.276 \\
\hline Between 3 (39) & 0.795 & 0.323 \\
\hline $\begin{array}{l}\text { Pooled } \\
\text { Between to poole }\end{array}$ & 0.774 & 0.177 \\
\hline
\end{tabular}

\section{HIINDEX_GEN*HIEDU_EQUAL*HIUNIV_BENEF}

\begin{tabular}{|c|c|c|}
\hline Between 1 (55) & 0.866 & 0.668 \\
\hline Between 2 (58) & 0.760 & 0.585 \\
\hline Between 3 (39) & 0.705 & 0.517 \\
\hline Pooled & 0.728 & 0.555 \\
\hline
\end{tabular}




\section{Results from robustness tests}

We present below a set of robustness checks performed on the main analysis (Oana \& Schneider, 2021). These are meant to check whether our results are sensitive to calibration decisions in the conditions (Table 9), and whether our analysis displays a particular sensitivity to the consistency threshold chosen for the outcome (Table 10).

Table 9: Robustness checks: sensitivity against calibration decisions

\begin{tabular}{lcccc}
\hline \multicolumn{4}{c}{ Sensitivity ranges } \\
\hline Condition & \multirow{2}{*}{ Bound } & \multicolumn{3}{c}{ Calibration anchors } \\
\cline { 3 - 5 } & & Exclusion & Cross-over & Inclusion \\
\hline \multirow{2}{*}{ HIINDEX_GEN } & Lower & - & 29 & - \\
& Upper & - & 29 & 38 \\
\hline
\end{tabular}

Table 10: Robustness checks: sensitivity to consistency threshold for LO_INEQ outcome

\begin{tabular}{lccc}
\hline \multirow{2}{*}{ Test } & \multicolumn{3}{c}{ Bounds } \\
\cline { 2 - 4 } & Lower & Threshold & Upper \\
\hline Raw consistency threshold & 0.7 & 0.7 & 0.7 \\
No. of cuts & 1 & 2 & 2 \\
\hline
\end{tabular}




\section{Question format for mechanism analyses}

To allow the reader to better assess the items we rely on for our mechanism analyses, we report here in Table 11 on page 21 the text of each item, along with the measurement scale used for it. The items are labeled with the survey program and wave they originate from, as well as the concept they tap into. We hope this facilitates an easy comparison with the mechanism figures in the main manuscript. 


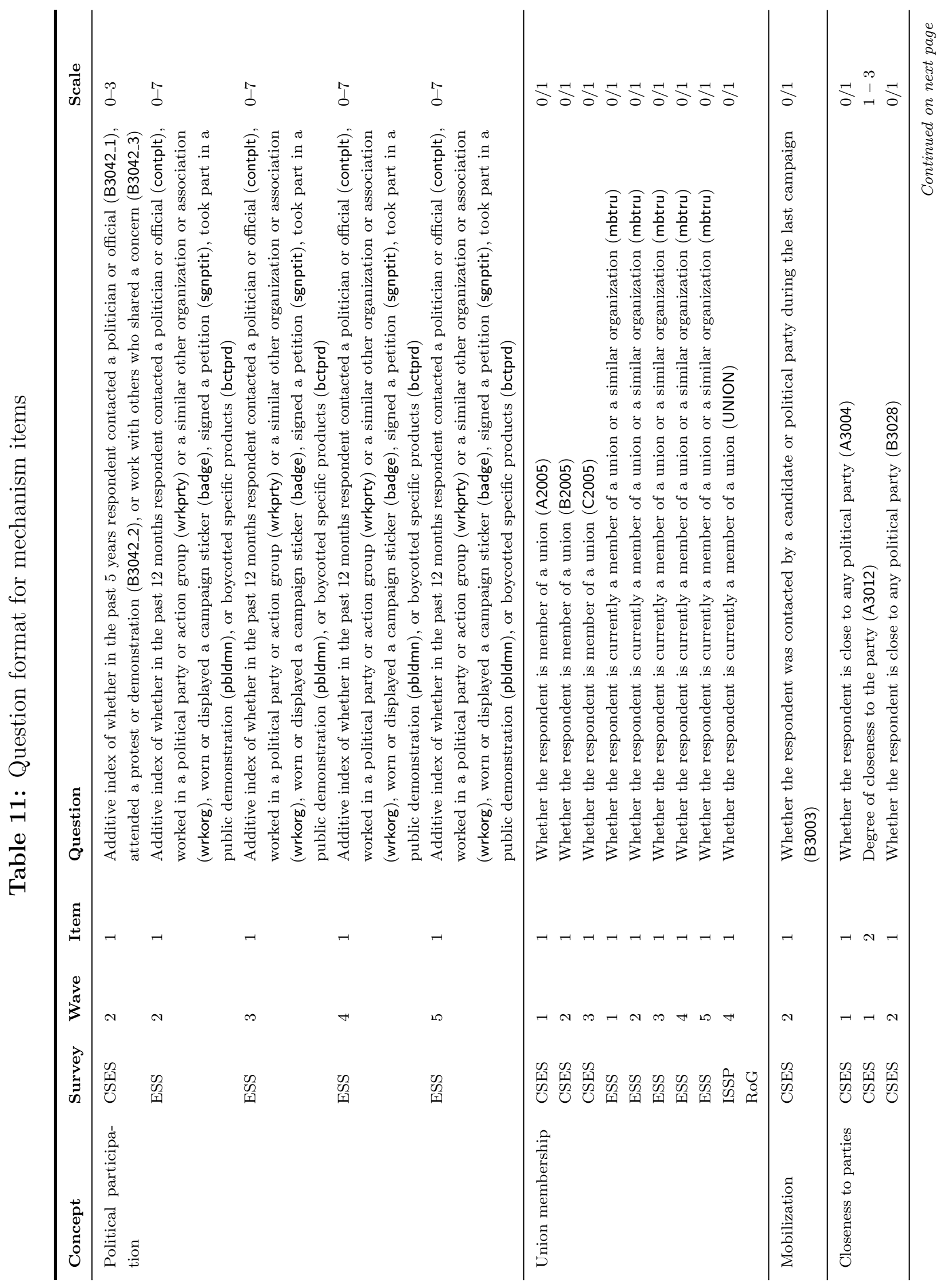




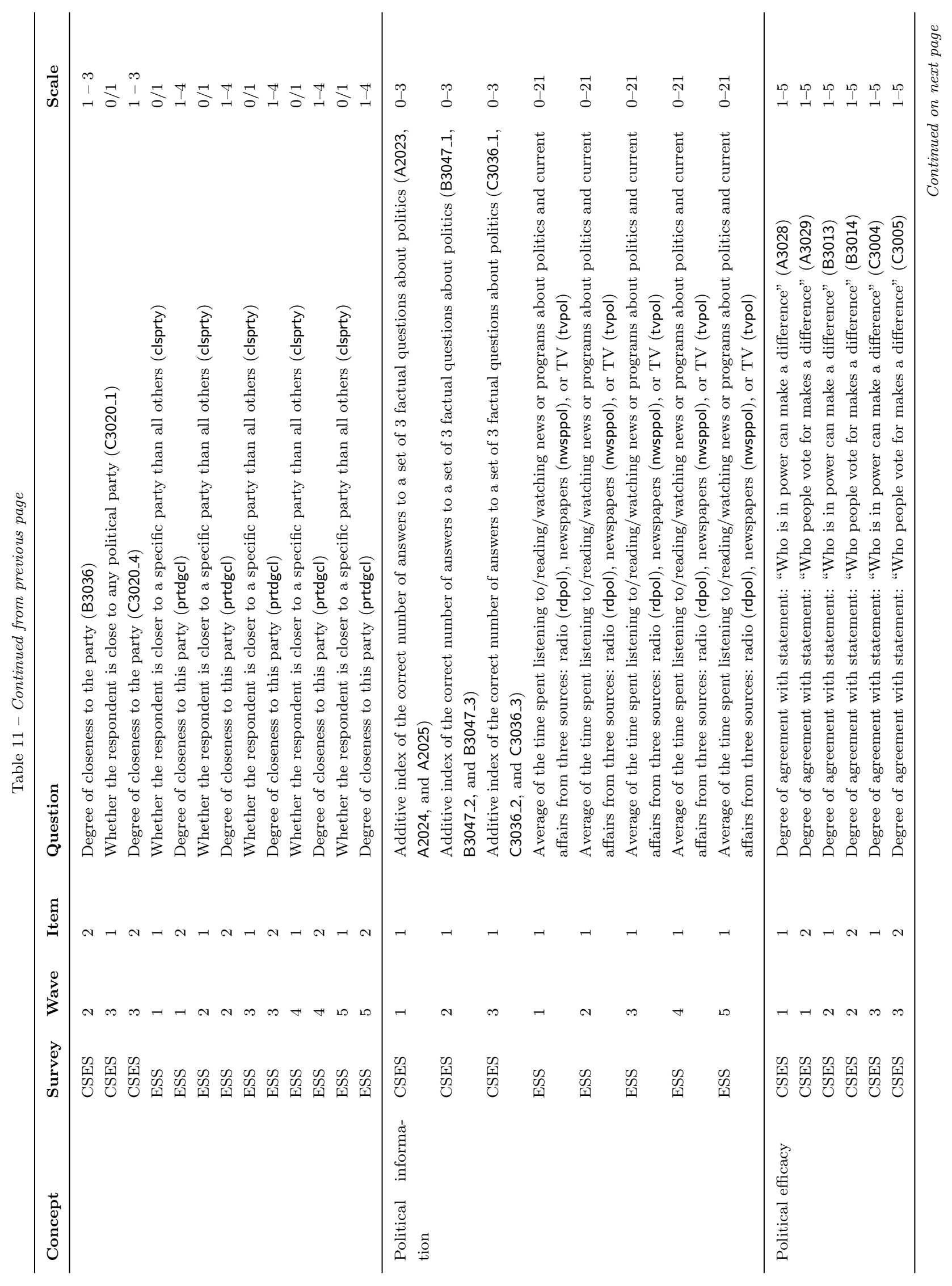




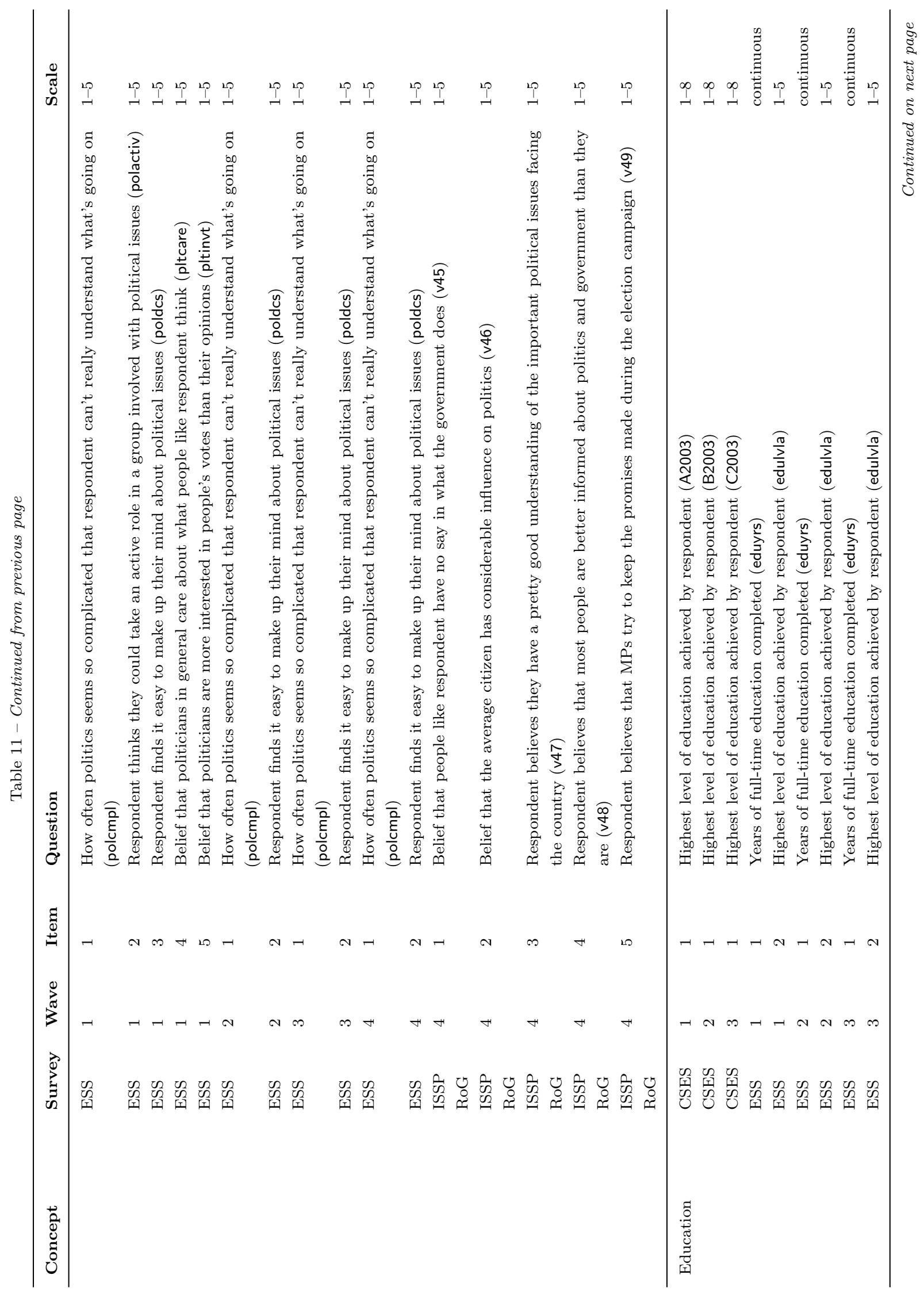




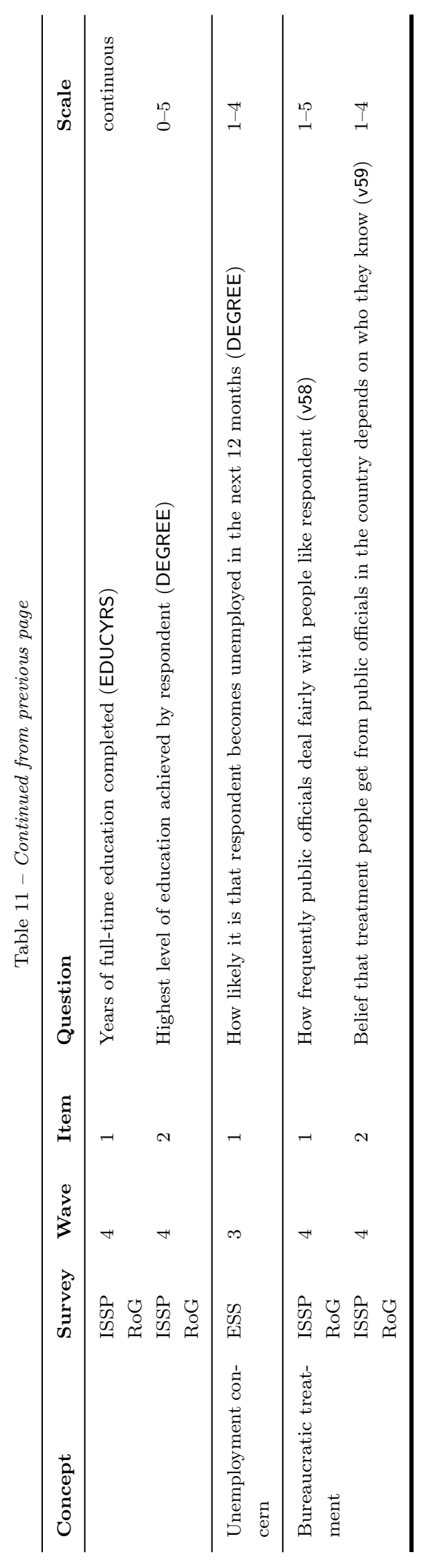




\section{Effect magnitude comparisons for mechanism analyses}

It is difficult to grasp the magnitude of the differences between citizens in different welfare regimes based only on the coefficients presented in Figures 4 and 5 in the main text. To overcome this, we also present the panels in Figure 2, which show the gaps between mobilizing and non-mobilizing regimes in terms of either the response itself, or the latent probabilities of membership in response categories. One example of this is presented in panel 2a, where we rely on the question about union membership found in wave 1 of the ESS. The panel depicts predicted probabilities of being a union member for low- and high-income respondents in both mobilizing and non-mobilizing countries identified in this wave of the ESS. We see that the gap in membership between income groups in mobilizing regimes is indeed slightly smaller than in non-mobilizing ones: nine percentage points (p.p.) compared to 12. Perhaps also relevant for our hypothesized link between union mobilization and turnout, though, low-income respondents in mobilizing regimes have higher membership rates than even highincome citizens of non-mobilizing regimes. We think this feature might also contribute to the narrower turnout gap we observe in the mobilizing cluster.

The other panels in Figure 2 present variations on the same dynamic. In the second panel (2b) we examine the probability of reporting feeling close to a political party on the spectrum. The gap between income groups in mobilizing regimes is about two p.p. compared to 11 p.p. in non-mobilizing ones, as we expected. We also see here, as in all the panels in the series, evidence for how our QCA factors operate by boosting levels of membership, or information, or efficacy particularly in those with lower incomes. ${ }^{5}$ In the last two panels in the figure, we encounter the same dynamic, though of lower magnitude. For political information the Y-axis presents the raw outcome, which was constructed as an index from three indicators that use ordinal scales to assess the frequency with which the respondent follows political news. We observe, for example, that aggregate levels of information in mobilizing regimes are higher than in non-mobilizing ones (panel 2c), and that low-income voters in the former are better informed about politics than even high-income voters in the latter. The difference between the two regimes is in the range of about $0.10-0.15$ points, and the standard deviation is about 1, suggesting a small-sized effect. Finally, we also see a narrowing of the gap in political efficacy between the two types of welfare regimes (panel 2d). In non-mobilizing regimes we observe the ranking we expect, with poorer respondents showing lower levels of efficacy than wealthier ones; in mobilizing ones, however, the two income groups are indistinguishable from

\footnotetext{
${ }^{5}$ It should be said that this is not always the case in our data; in some instances, the lower gap between income groups in mobilizing regimes compared to non-mobilizing ones is due to a greater decrease in the outcome for the high-income group.
} 
each other, and this development is driven more by the greater increase in efficacy levels of poorer citizens. ${ }^{6}$

Figure 2: Effect magnitude comparisons for mechanisms in mobilizing regimes

(a) Union membership

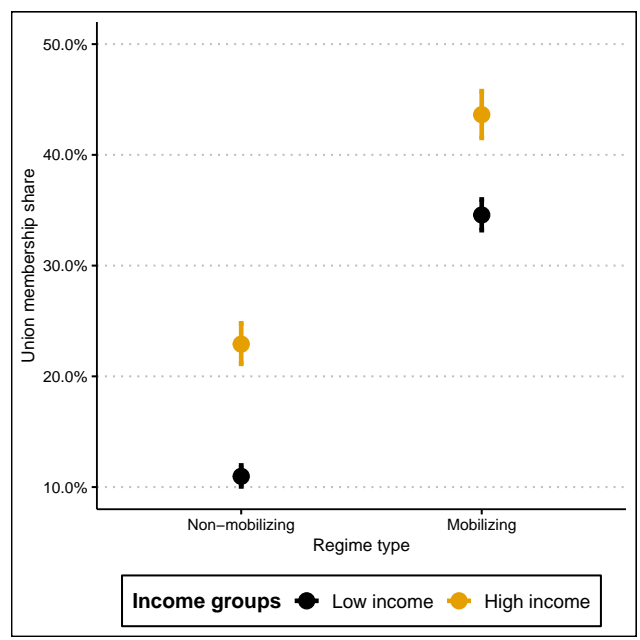

(c) Political information

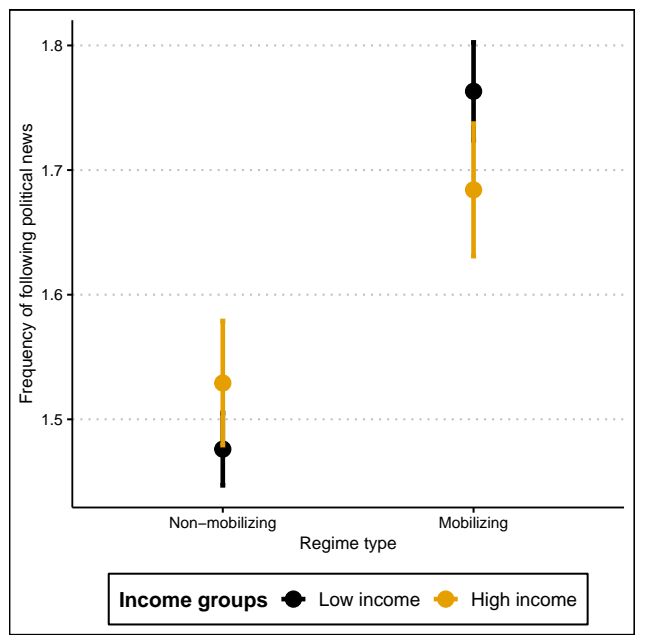

(b) Closeness to parties

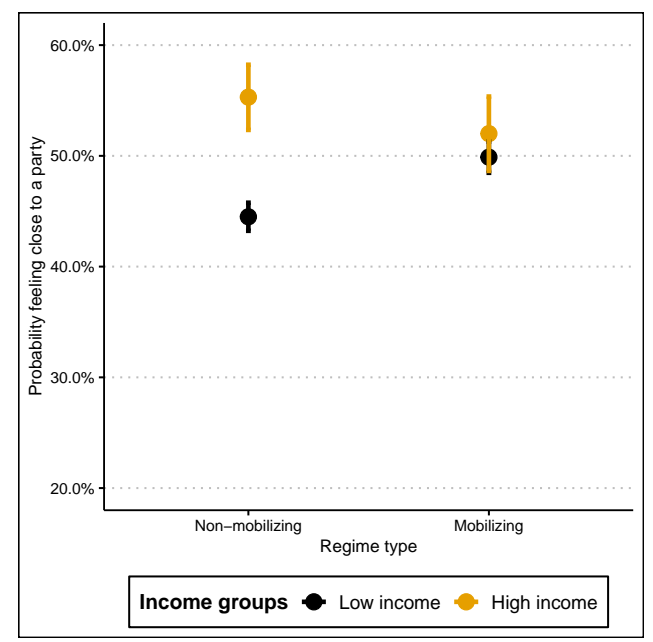

(d) Political efficacy

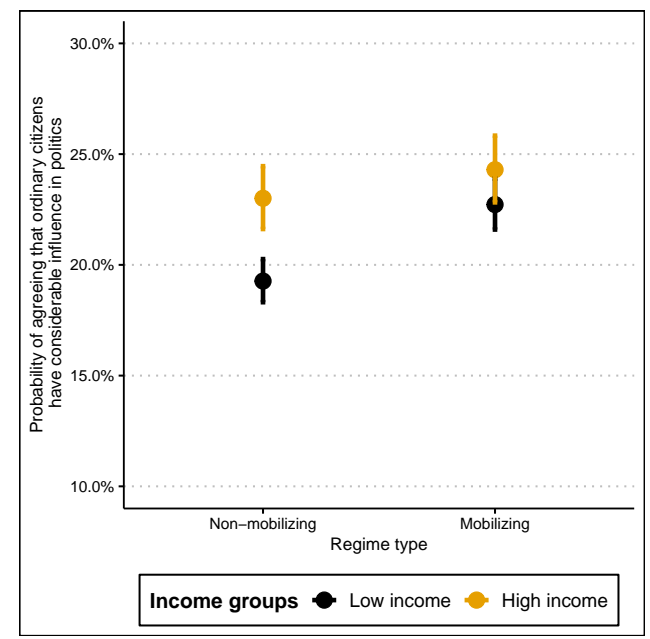

Notes: ${ }^{(1)}$ For union membership we use the item available in wave 1 of the ESS. This records the membership of the respondent on a 3-point scale: yes, currently; yes, previously; and, no. For our analysis we collapse "yes, previously" and "no" into a single category. ${ }^{(2)}$ For feelings of closeness to parties we use the item available in wave 1 of the CSES. This inquires whether the respondent generally thinks of themselves as close to any political party, using a simple dichotomous scale: "yes" and "no".

(3) For political information we rely on information found in wave 5 of the ESS. We construct an index by averaging responses about frequency of daily political news consumption from 3 mediums: TV, radio, and newspapers. For each of these channels, the frequency is measured on an 8-point scale: no time at all; less than $0.5 \mathrm{hr} ; 0.5-1 \mathrm{hr} ; 1-1.5 \mathrm{hrs} ; 1.5-2 \mathrm{hrs} ; 2-2.5 \mathrm{hrs}$; $2.5-3 \mathrm{hrs}$; more than 3 hrs. ${ }^{(4)}$ For political efficacy we use one of the items available in wave 4 of the Role of Government module from the ISSP. This measures the respondent's agreement with the fact that the average citizen has a considerable degree of influence on politics, on a 5-point scale: strongly disagree; disagree; neither agree nor disagree; agree; and, strongly agree.

\section{A similar presentation for the contrast between supportive and globally uncovered cases is}

${ }^{6}$ It's important to specify that panel $2 \mathrm{~d}$ presents the probability of membership in only one of the outcome categories: "agree". In this case, the outcome was measured on a 5-point scale, ranging from "strongly disagree" to "strongly agree". 
made in Figure 3, though here we focus only on education and political efficacy from Figure 5 in the main text, as they are the only ones for which (weak) evidence of an effect was uncovered. In both panels we depict the probability of membership in only one category of the outcome: for education this is having graduated with a tertiary degree, while for political efficacy it is believing that "some" politicians care about what people similar to the respondent think. For education we rely on the test from wave 3 of the ESS, while for political efficacy we use wave 1 from the same source. Though in both cases we see a narrower gap between income groups in supportive regimes than their non-supportive counterparts, this is of relatively small magnitude. In non-supportive regimes the efficacy gap is about 11 p.p., whereas in supportive ones this narrows to four p.p. The corresponding gaps in the case of educational achievement are 30 and 28 p.p.

Figure 3: Effect magnitude comparisons for mechanisms in supportive regimes

(a) Educational achievement

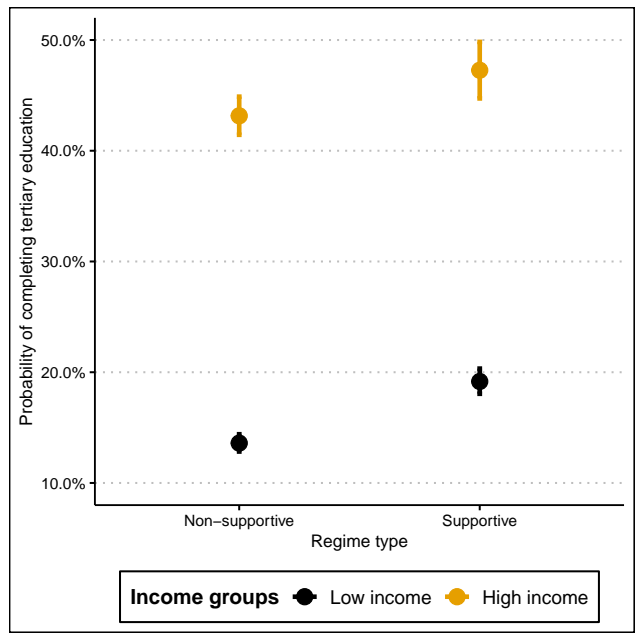

(b) Political efficacy

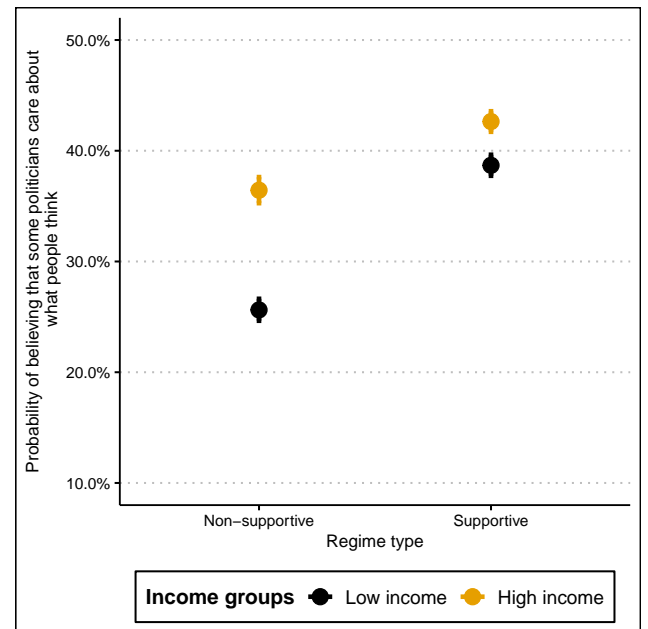

Notes: ${ }^{(1)}$ For education we use the item available in wave 3 of the ESS, recording the highest educational level achieved on a 5-point scale: less than lower secondary, lower secondary completed, upper secondary completed, post-secondary non-tertiary completed, and tertiary completed. ${ }^{(2)}$ For political efficacy we use one of the items available in wave 1 of the ESS. This records the respondent's belief of how many politicians care what people similar to the respondent think, on a 5-point scale: hardly any, very few, some, many, or most. 


\section{References}

Oana, I.-E., \& Schneider, C. Q. (2021). A Robustness Test Protocol for Applied QCA: Theory and R Software Application. Sociological Methods \& Research. doi: 10.1177/ 00491241211036158

Oana, I.-E., Schneider, C. Q., \& Thomann, E. (2021). Qualitative Comparative Analysis Using R: A Beginner's Guide. Cambridge, MA: Cambridge University Press.

OECD. (2005). Education at a Glance: OECD Indicators 2005 (Tech. Rep.). Paris: Organization for Economic Cooperation and Development.

Schmitt, H., Önnudóttir, E. H., Teperoglou, E., \& Vegetti, F. (2013). The True European Voter: Micro Data Codebook. Mannheim University: Mannheimer Zentrum für Europäische Sozialforschung. 